\title{
Does religion shape people's sense of humour? A comparative study of humour appreciation among members of different religions and nonbelievers
}

\author{
Karl-Heinz Ott \\ Expertbioinformatics, LLC, Belmont, MA \\ ottk@expertbioinformatics.com
}

\author{
Bernard Schweizer \\ Long Island University \\ bernard.schweizer@liu.edu
}

\begin{abstract}
Using an empirical approach, this study addresses the question whether followers of different religious beliefs (Christians, Muslims, and Hindus), as well as Atheists and Agnostics manifest different senses of humour when rating a variety of jokes. The study further investigates whether one's religious background influences the threshold of what is considered offensive. And finally, it seeks to answer whether jokes targeting religions other than one's own are always perceived as funnier. Analysing the results of a public survey $(N=783)$ containing a blend of religious and non-religious jokes (including irreverent ones), we found that Hindus demonstrate overall the highest humour appreciation among all the groups, while Christians were the least amused by the jokes presented on the survey. Muslims had overall robust humour responses, despite reporting the highest incidence of being offended. Atheists were the least likely to be offended, and they generally enjoyed irreverent jokes. All groups agreed that if a joke was seen as offensive, its funniness was reduced.
\end{abstract}

Keywords: Christian, Muslim, Hindu, Atheist, Agnostic, humour appreciation.

\section{Introduction}

The reaction of different religious populations to religious and religiously-offensive humour is subject to strong public opinions (e.g. Kuipers 2011; Burridge 2015), extensive journalistic coverage (e.g. Khan 2007; Merritt 2015), and substantial scholarly discussion (Siegel 1987; Kuschel 1994; Berger 1997; Morreall 1999; Elst 2011; Martin 2011; Marzolph 2011; Zimbardo 2014; Hirzalla \& van Zoonen 2016). This study contributes evidence from a wellpowered survey to provide an empirical standard against which historical generalisations, 
speculative arguments, and plain opinions on the link between religion and humour can be measured. By analysing humour appreciation patterns of entire populations, our work deviates from the recent trend in quantitative humour studies to focus mainly on effects of humour in the context of personal psychology and individual differences (e.g. Martin et al. 2003; Stieger et al. 2011; Maiolino \& Kuiper 2016; Ford et al. 2017). Instead, our study adds to the modest but growing body of research about shared humour sensibilities (e.g. Yue 2011; Braun \& Preiser 2013; Abrams et al. 2015; Schweizer \& Ott 2016). Specifically, this study provides empirical answers to the question whether, collectively, Muslims, Christians, Hindus, Agnostics, and Atheists demonstrate observable and statistically relevant differences in their appreciation of humour, including their reaction to irreverent jokes.

In the context of Christianity, some contemporary theologians express concern that official Christianity's long-standing hostility to laughter has led to a religious climate of joylessness: "Even if many priests and ministers admit the need for joy, many religious institutions still seem to find little room for a smile, a joke, laughter, or the occasional measure of silliness" (Martin 2011: 147). This phenomenon has a long historical pedigree. Theologian Karl-Joseph Kuschel writes about "a line of tradition which really existed, from John Chrysostom through Augustine to Bernard of Clairvaux and Hugo of St Victor, of the Christian denunciation of laughter" (1994: 43). As regards Islam, mass protests against cartoons in Islamic nations and a string of violent attacks by Islamist terrorists against satirical institutions and irreverent jokesters has nurtured the idea that Islam has a basic problem with humour (Zimbardo 2014; Hirzalla \& van Zoonen 2016). One commentator notes that

[c]ontemporary popular opinion in the West strongly advocates the dominant perception that Muslim tradition in its perceived religious zeal does not allow for such a subtle and tolerant trait of character as humour - in other words: that Muslims don't have a sense of humour.

(Marzolph 2011: 171).

By contrast, several scholars working in the sociology and history of humour have argued that eastern religions, especially Hinduism, are particularly accommodating of laughter and that humour even functions as a natural attribute of their religious practices (Siegel 1987; Morreall 1999; Elst 2011). Finally, it can be speculated that nonbelievers and sceptics are differently socialised in terms of humour, possibly being more uninhibited when it comes to responding to instances of humour, including blasphemous humour. As a truly interdisciplinary study, this paper goes beyond engaging only the field of quantitative humour appreciation and addresses the wider context of social and cultural constructions of humour, even making an intervention in public and political discourses about humour and religion.

It is clear that many factors besides religion may influence the sense of humour, including social class, educational background, ideology, and age. This study operates with a large sample size and carefully evaluates the possible contribution of such secondary or confounding factors. It also blinds itself to prior perceptions and biases regarding the relationship between humour and religion to focus exclusively on a data-driven approach to answer the following four research questions:

1. Are there statistically significant differences in humour appreciation between members of major denominational/historical religious traditions and people with no religion?

2. Does religious belief affect people's sensitivity toward irreverent (religiously offensive) jokes?

3. How does the perceived offensiveness of irreverent jokes affect their funniness?

4. Do people rate the funniness of offensive jokes targeting their own religion differently from jokes targeting other religions? 


\section{Methods}

\subsection{The survey}

Our data was generated by a survey, whose participants read an introductory paragraph about the general topic of the survey, followed by 24 jokes and cartoons, each joke accompanied by a response section to rate the funniness, offensiveness and comprehension (see Appendix A). 18 jokes addressed religious topics, targeting Christians, Muslims, and Jews, while 6 nonreligious jokes were included as a control. The survey contained a blend of both text-based jokes and amusing photos and cartoons, and it balanced witty, good-natured jokes with highly irreverent ones.

Funniness was rated on a nine-answer-five-category scale from "Not funny" to "Hilarious". This rating scheme is deliberately skewed toward funniness to avoid the impression that the middle option signified "neutral" or "N/A". ${ }^{1}$ Further, our rating scale was intended to mimic a seamless slider by introducing "midpoints" between labelled answers. ${ }^{2}$

We also inquired about the perceived offensiveness of each joke, with the two options: "This is offensive to me" or "This is not offensive to me." Finally, we assessed the participants' understanding of each joke with the three options: "I got this joke"; "I had to think"; "I did not get this joke."

\subsection{Demographic Information}

After rating the 24 jokes, participants encountered a series of questions pertaining to their demographics, the most important of which are summarised in Table 1. In terms of gender, the sample was reasonably well balanced. Geographically, the vast majority of the survey participants live in the United States, with two exceptions: 97\% of Hindus reported from India, and the Muslims were almost split evenly between India and the United States (see note about confounding below). Participants reporting from Europe and other regions constituted negligible numbers. More than two thirds of the participants were in the 20-39 age category, and the majority of them were politically liberal (with the exception of the Christians). Although not entirely homogenous, this makes for a sample population that is demographically quite compact, with moderate possibility of confounding due to disparities in age, ideology, and region.

\begin{tabular}{|l|r|l|l|l|l|l|l|l|l|l|l|}
\hline Religion & $\mathrm{N}$ & \multicolumn{3}{|l|}{ Gender } & \multicolumn{2}{l|}{ Age } & \multicolumn{2}{l|}{ Region } & \multicolumn{3}{|l|}{ Ideology } \\
\hline & & Female & Male & $\begin{array}{c}20- \\
39\end{array}$ & $\begin{array}{c}40- \\
59\end{array}$ & $>60$ & USA & Asia & $\begin{array}{c}\text { Eu- } \\
\text { rope }\end{array}$ & Liberal & $\begin{array}{c}\text { Con- } \\
\text { serv. }\end{array}$ \\
\hline Christianity & 153 & $57 \%$ & $43 \%$ & $60 \%$ & $29 \%$ & $11 \%$ & $89 \%$ & $7 \%$ & $2 \%$ & $46 \%$ & $54 \%$ \\
\hline Islam & 57 & $29 \%$ & $71 \%$ & $95 \%$ & $5 \%$ & $0 \%$ & $50 \%$ & $41 \%$ & $3 \%$ & $60 \%$ & $40 \%$ \\
\hline Hinduism & 52 & $31 \%$ & $69 \%$ & $79 \%$ & $19 \%$ & $2 \%$ & $2 \%$ & $97 \%$ & $0 \%$ & $64 \%$ & $36 \%$ \\
\hline Atheist & 80 & $40 \%$ & $59 \%$ & $68 \%$ & $25 \%$ & $7 \%$ & $87 \%$ & $5 \%$ & $7 \%$ & $78 \%$ & $22 \%$ \\
\hline Agnostic & 100 & $47 \%$ & $52 \%$ & $71 \%$ & $22 \%$ & $6 \%$ & $97 \%$ & $2 \%$ & $1 \%$ & $76 \%$ & $24 \%$ \\
\hline Non-practicing & 72 & $54 \%$ & $46 \%$ & $54 \%$ & $34 \%$ & $9 \%$ & $81 \%$ & $19 \%$ & $0 \%$ & $63 \%$ & $37 \%$ \\
\hline Control & 254 & $45 \%$ & $55 \%$ & $67 \%$ & $25 \%$ & $7 \%$ & $86 \%$ & $12 \%$ & $2 \%$ & $64 \%$ & $36 \%$ \\
\hline Other & 17 & $78 \%$ & $22 \%$ & $56 \%$ & $44 \%$ & $0 \%$ & $78 \%$ & $22 \%$ & $0 \%$ & $65 \%$ & $35 \%$ \\
\hline All & 783 & $46 \%$ & $54 \%$ & $68 \%$ & $25 \%$ & $2 \%$ & $79 \%$ & $12 \%$ & $3 \%$ & $63 \%$ & $37 \%$ \\
\hline
\end{tabular}

Table 1: Basic demographics of the study. (Not all categories are reported).

In order to operationalise unambiguous religious identity categories and to keep the number of variables within reasonable bounds, we opted to apply generic denominational labels. Thus, 
survey-takers were asked to self-identify in the following categories: Christian, Muslim, Hindu, Mormon, Buddhist, and Jew. On the sceptical side, the self-identification menu contained the categories Atheist, Agnostic, as well as non-practicing member of each of the offered faiths. We decided not to offer the option "Nones" since this label is primarily employed by sociologists and does not constitute a self-evident identity category chosen by people (i.e. nobody says "I am a None"3). A separate sample of the first quarter of participants, together with participants who indicated "Other" as their religion, was used as a reference point for the statistical analysis (named "Control" in the Figures and Tables). ${ }^{4}$

The various sub-populations are represented unevenly, which is unavoidable given the mode and avenue of administering the survey. ${ }^{5}$ We set a minimal floor of 50 participants for the analysis by group to ensure reasonable statistical power. As a result, responders classifying themselves as Jews, Buddhists, and Mormons, were grouped as "Others" since none of them posted more than a handful of returns; they were included as part of the Control group. ${ }^{6}$

\subsection{Data collection and quality control}

We collected 1077 surveys between January 22 and 28, 2016, using Qualtrics.com as our online platform to administer the survey. We recruited the participants via the crowdsourcing service Amazon Mechanical Turk (AMT). The cash reward for this "Human Intelligence Task" (HIT) was 51 cents per MTurk worker.

Notwithstanding some criticism (Rouse 2014), several replication studies have generally confirmed the reliability of data obtained via AMT (Rand 2011: 4-5). Crump et al. (2013: 16) "recommend that reviewers and editors should consider accepting behavioural experiments done on AMT as a valid methodology". And Mason \& Suri $(2012: 1,3)$ found that "when taken as a whole Mechanical Turk can be a useful tool for many researchers", with one of the distinctive advantages being that "the workers tend to be from a very diverse background, spanning a wide range of [demographics]" "beyond the undergraduate population". This study has reached a diverse but yet still compact set of younger participants, with little apparent bias other than a natural confounding between Hindu religion and Indian origin.

To improve data quality often criticised in AMT studies, we developed a number of best practices for a strict, but unbiased filtering and validation scheme to remove unreliable returns. Specifically, we filtered 101 surveys for repeat submissions from the same IP address (retaining the second submission); we excluded 74 surveys that took less than three minutes to complete (while the median survey took about 6 minutes); we eliminated surveys that seemed to be "mechanically" (monotonously) filled by removing the 54 participants with the lowest five percentile of the standard deviation $(<=0.9033)$ among the funniness rating. We also removed 103 meaningless surveys where the majority $(\geq 14)$ of jokes were indicated as "not understood"; we dismissed 16 surveys that had more than half of all jokes marked as offensive; and we discounted 20 participants that failed the attentiveness test. After combining all the filters (62 respondents were caught in multiple filters), the number of surveys dropped from 1077 to 783. Most groups had between 22\% (Agnostics) and $27 \%$ (Atheists) of respondents removed, but Hindus had 37\% of their respondents removed. The proportion of $28 \%$ bad surveys gives support to some of the critique regarding AMT. Crossvalidation of the data (not shown) leads us to estimate the remaining "noise" level at about $5 \%$, thereby in the range of controlled studies. After filtering, we had between 52 and 153 passing surveys each to represent the populations of Christians, Muslims, Hindus, Atheists, Agnostics, and non-practicing believers, as well as an independent control population of 254 participants. 


\subsection{Masking}

The qualification question about comprehension of the jokes was introduced to avoid skewing and invalidating the responses due to cultural or educational disparities. In this masking process, individual responses of a participant for a particular joke marked by the participant as "I did not get it" were ignored (i.e. treated as a missing value) in all analyses. This masking is rationalised by the assumption that someone cannot rate a joke in a meaningful way if that person does not understand its meaning. (Obviously, that does not correct for different interpretations of a joke.)

\subsection{Statistical analysis}

The answer counts after filtering and masking were summarised for each major population and normalised as needed to allow for comparison of various subgroups. Average funniness responses were calculated based on the filtered responses. The distribution of responses was analysed using ordered logistic regression after filtering and masking. Overall, the responses produced a multimodal response pattern, where unnamed "half-points" in-between the named answer options were chosen less frequently. Such data could not be reliably fitted. Moreover, significant correlation was found between many adjacent answer categories. Based on this analysis, a binning of the answers into five categories was chosen: Response 1: Bin A; response 2-4: Bin B; response 5, 6: Bin C; response 7: Bin D; response 8, 9: Bin E. Such binning resulted in a response pattern that promised no loss of information but instead produced an increase in statistical power.

\section{Results}

\subsection{Result summary}

After filtering and masking, a total of 17,179 non-empty answers remained. Of those, 2,161 $(12.5 \%)$ were labelled as "offensive". The highest proportion of offensive votes came from Muslims (24\%), followed by Hindus (20\%) and Christians (18\%). A total of 1,569 answers $(9.1 \%)$ indicated that the joke was not understood. 


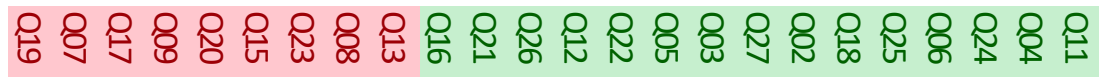

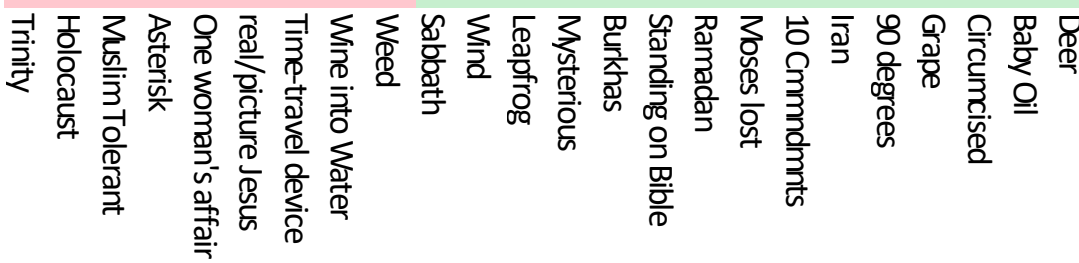

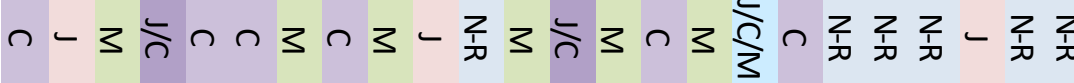

Target

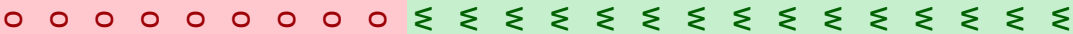

W/O

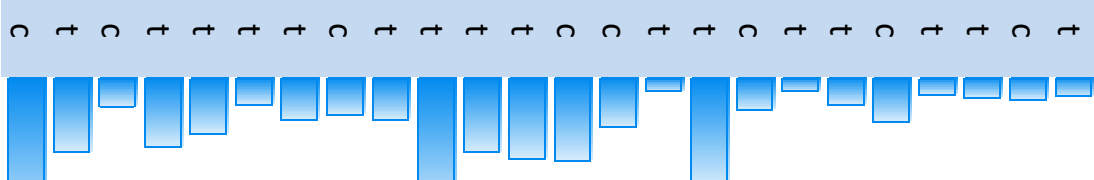

Text/

Cartoon

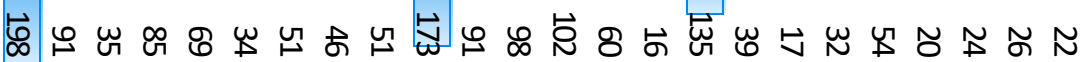

Not understood

$\overbrace{\substack{0 \\ 0}}^{0}$

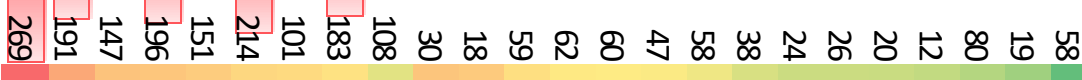

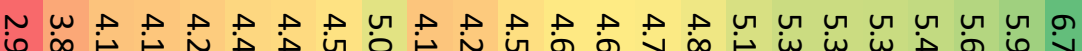

Offensive Votes

Funniness

Average

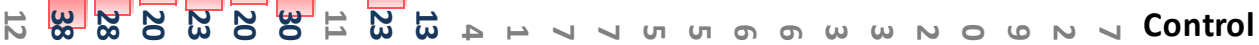

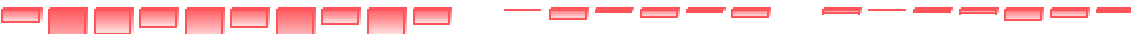

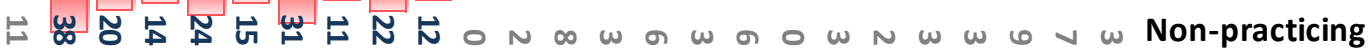

u

G

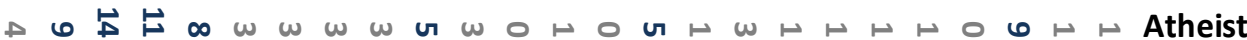

$\square$

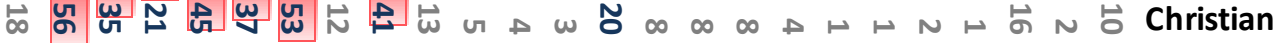

ก

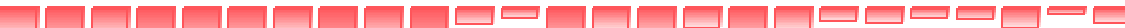

I

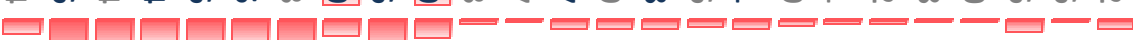

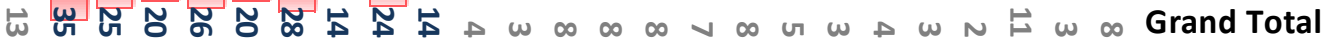

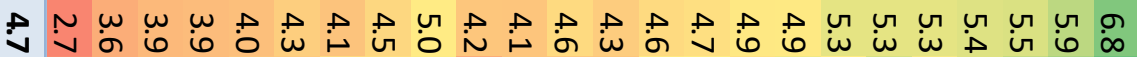

Control

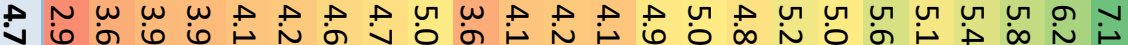

Non-practicing

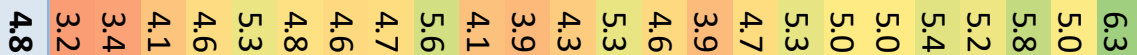

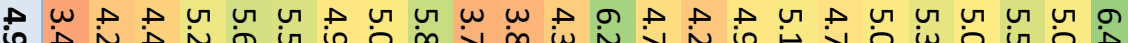

Agnostic

Atheist

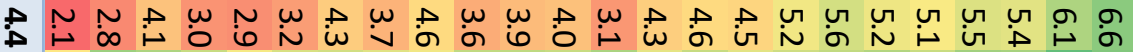

Christian

U

Hindu

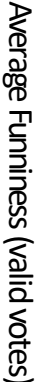

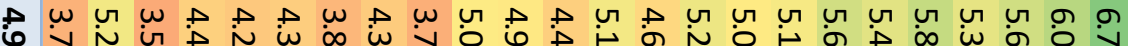

Muslim 
Table 2: Summary of study design and results. For each joke (Q, Name), the table lists (left to right) the group being targeted $(\mathrm{N}-\mathrm{R}=$ non-religious, $\mathrm{J}=\mathrm{J}$ ews, $\mathrm{M}=$ Muslims, $\mathrm{C}=\mathrm{Christians})$; the a priori offensive (o) or witty (w) classification; the medium (Text (t) or Cartoon (c)); the number of participants stating they did not understand the joke; the number of all participants (votes) who characterized the joke as offensive; the average funniness rating of all participants on the original 9-point scale; the percent of offensive classifications (separated by group and given relative to the total number of valid classifications in each cell); and the average funniness score of the valid votes separated by sub-population.

The average funniness rating of the 24 jokes (Table 2) reached as high as 6.7 (out of 9 points) for Q11-Deer and dropped as low as 2.9 for the most offensive and most-non-understood joke (Q19-Trinity). Most of the more offensive jokes registered with lower average funniness ratings, except 13-Weed, while 16-Sabbath and 21-Wind were generally not found to be funny, albeit not offensive either. The least-understood jokes were very religion-specific (3Ramadan, 16-Sabbath, and 19-Trinity) with 135, 173, and 198 respondents, respectively, indicating they did not understand those jokes. The most offensive jokes were 19-Trinity (269 offensive votes), 15-Jesus picture (214 offensive votes), 9-Asterisk, and 8-Wine into water with over 180 offensive votes, followed by 20 -One woman's affair (151 offensive votes) and 13-Weed (108 offensive votes).

\subsection{Research Question 1: Are there statistically significant differences in humour appreciation between groups with different religious views or with no religion?}

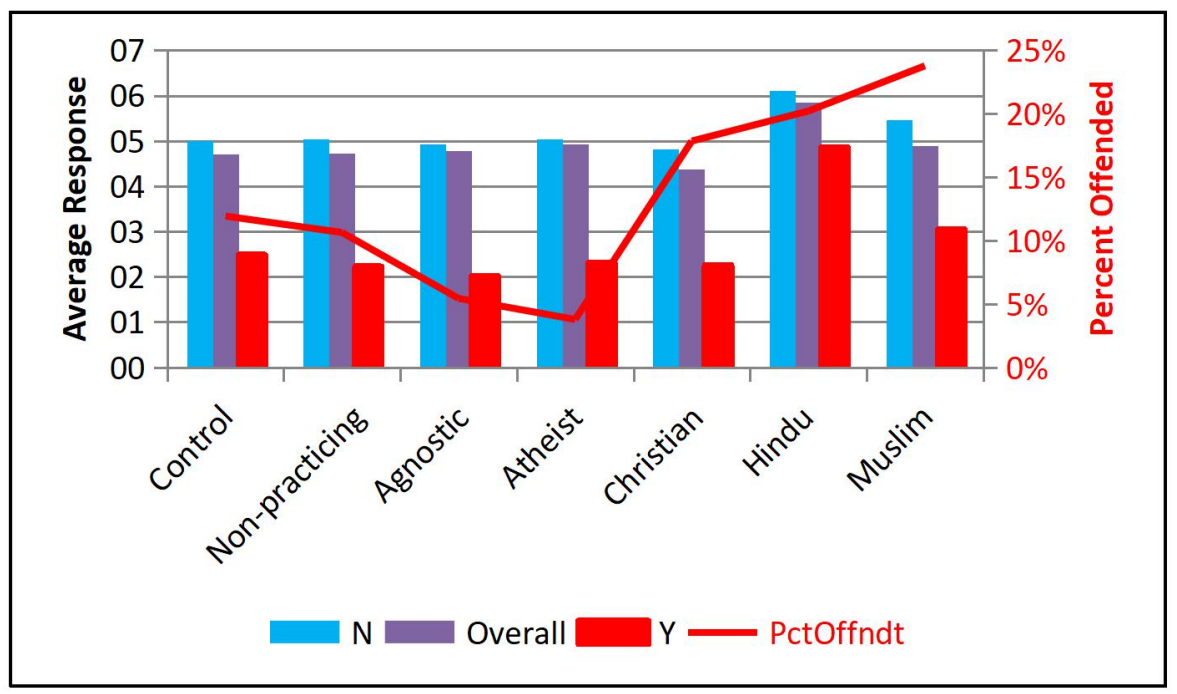

Figure 1: Average funniness ratings across all 24 jokes, displayed by sub-population (purple bars, left axis), and separately for responses designated as "offensive" (red bars) and "not offensive" (blue bars). The percentage of offensive votes is depicted as a red line on the right axis.

Figure 1 demonstrates the average responses of all populations to the totality of 24 jokes, separated by whether the respondents indicated "offensive" or "non-offensive". Hindus rate the funniness of the jokes significantly higher (Difference $>0.9, p<<0.001$ by ANOVA) than all other populations while Christians produced significantly lower average ratings (Difference $<-0.35, \mathrm{p}<<0.001$ ). The average funniness across all 24 jokes of Muslims, 
Atheists, Agnostics, Non-practicing believers, and Control was about the same (Difference $<0.25, \mathrm{p}>.3$ ) and none of the pairwise comparisons between those groups (by t-test) shows any significant differences.

Every population judged non-offensive jokes to be distinctly funnier than offensive ones. The average funniness rating dropped by about 2.3 points on the 9-point funniness scale when jokes where deemed offensive. The percentage of survey-takers who recorded an "offensive" vote was very low for Atheists and Agnostics. Surprisingly, those few Atheists who did indicate that they were offended tended to rate the funniness of the offensive jokes lower by as much as did Christians and non-practicing believers, i.e. almost 3 units on the funniness scale. Muslims recorded the highest percentage of "offended" votes among all religious groups, followed by Hindus and Christians. The Hindu population both voted the totality of all 24 jokes on average as the funniest while at the same time also registering the second-highest percentage of "offended" votes. That is to say, after voting "offended", Hindus still accorded the offensive jokes a higher degree of funniness than the other groups since the drop in funniness rating is considerably less compared to all other groups.

Our earlier comparative study about humour appreciation among Christians and Atheists (Schweizer \& Ott 2016) found that these two groups largely agreed in their basic humour appreciation, with two exceptions: highly offensive religious jokes were significantly more funny to Atheists than they were to practicing Christians, while Atheists were less amused than Christians by good-natured religious jokes that were predicated upon faith. In the present study, responses from Atheists and Christians were also undistinguishable when the two groups responded to non-offensive jokes. But just as in the previous study, Atheists again rated the highly irreverent Christian-targeting jokes (Figure 2; red markers) on average significantly more funny than Christians did (red regression line). And Christians again showed greater enthusiasm than Atheists did for mild, good-natured Christian jokes that poke fun at simple flaws or weaknesses of believers (e.g. Q02-Commandments, Q05-Standing). Compared to Atheists, Christians also slightly disfavour jokes targeting Islam, (Figure 2, green-dotted grey markers).

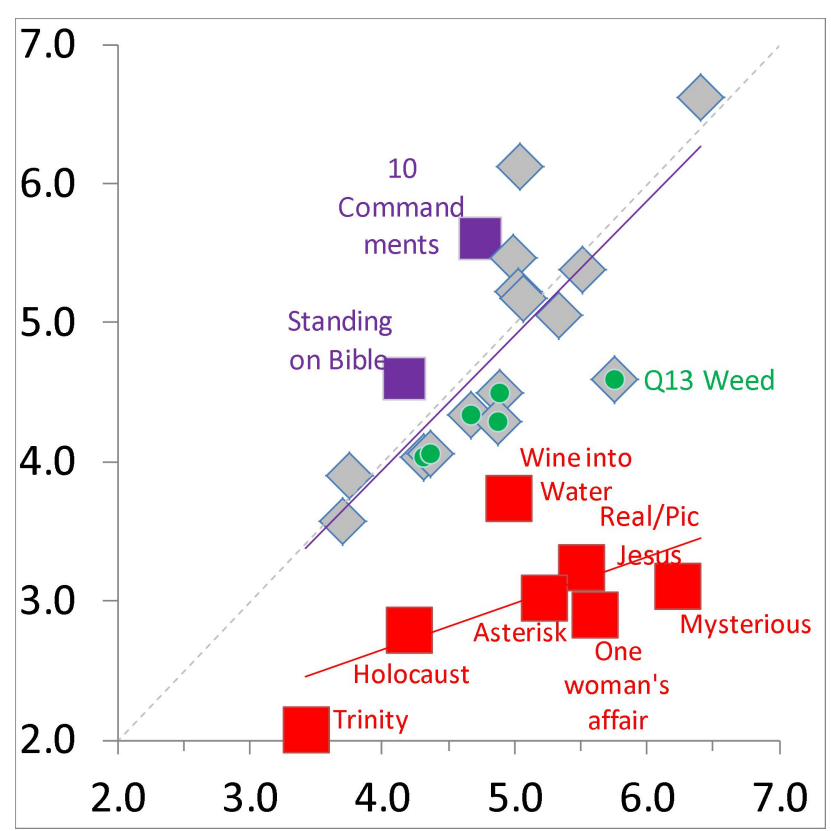

Figure 2: Correlation of average funniness ratings between Christians (y-axis) and Atheists (x-axis). Jokes offensive to Christians (red markers and red regression line). Purple regression 
line for witty (grey markers) and Islam-targeting jokes (grey markers with green dots). Purple markers indicate benign religious jokes. The dotted grey line represents the diagonal.

Moving away from computing averages for whole populations - which is a rough indicator of humour appreciation-Figure 3 presents the distribution of frequencies with which the participants chose the five answer options. The responses for all 783 participants follow a distribution, with the flat peak located at the second option ("Slightly funny"). The majority of responses for jokes that were individually rated as offensive resulted in "Not funny" votes.

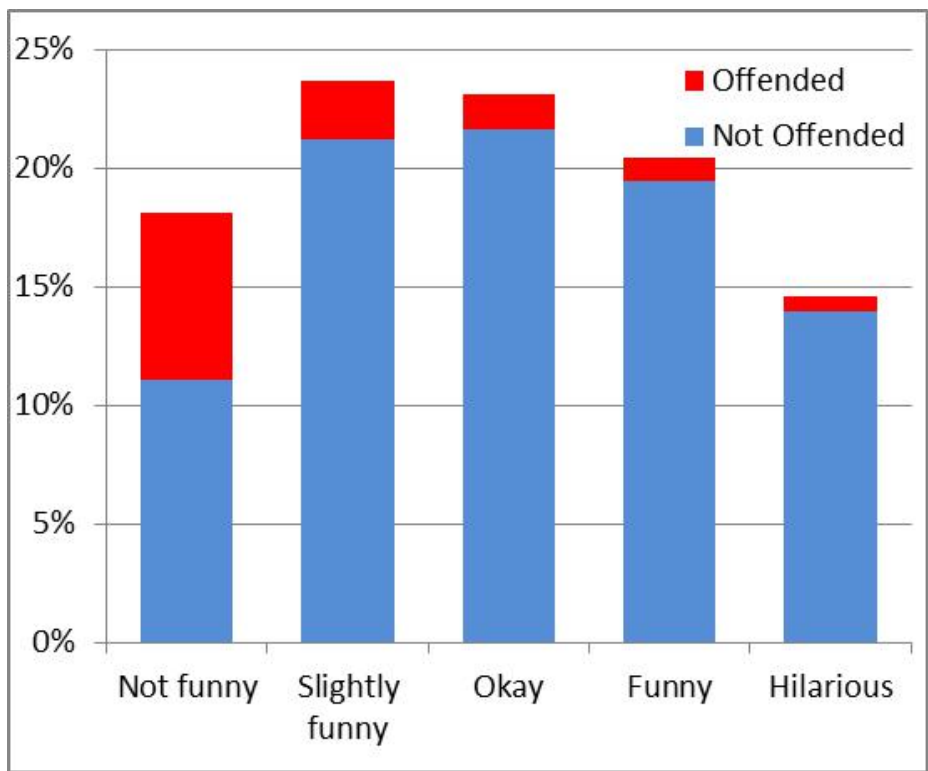

Figure 3: Binned distribution of all valid responses with the portion of responses classified as offensive indicated in red.

When examining the patterns of responses to jokes that are considered not offensive (Figure $4 \mathrm{~A}$ ) as a function of religious group, we find that the increase in funniness rating by Hindus is due to a strong drop in the use of "Not funny" and "Slightly funny" votes. For those who are offended (Figure 4B), Christians, Agnostics, and Non-practicing respondents chose "not funny" in about $70 \%$ of all cases, while almost an equal percentage of Hindus selected the three highest funniness ratings for the jokes they deem offensive. 


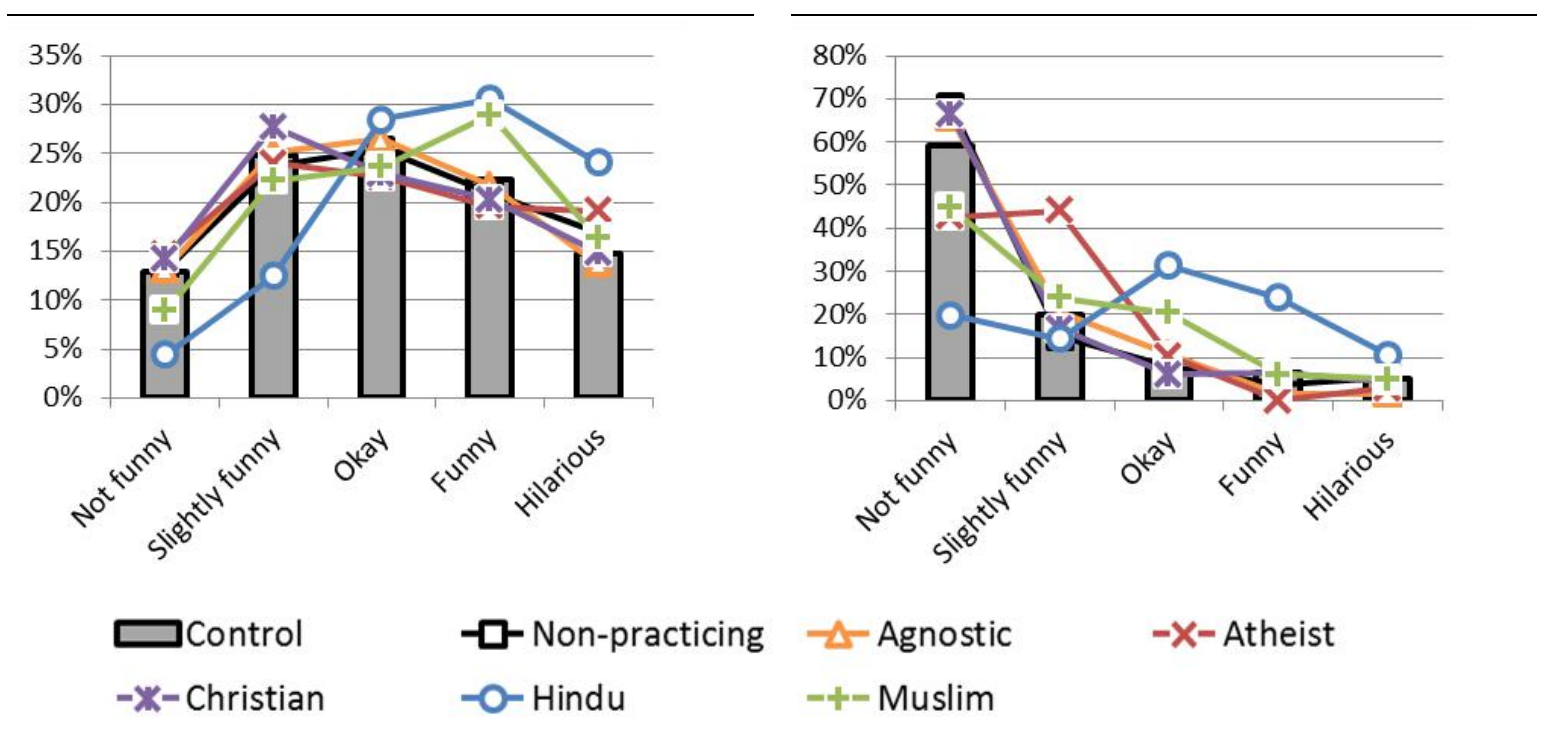

Figure 4: Frequency distributions of binned responses for each religious group (lines, with religion indicated by the colour coding). Grey bars represent the response option frequencies of all participants ( $\mathrm{N}=783)$, including all votes (not sorted by offensive or nonoffensive). Frequencies are normalised within each group, i.e. the total of all frequency of each religion is $100 \%$. A) Left: Responses to jokes marked as non-offensive. B) Right: Responses to jokes marked as offensive.

Ordered logistic regression analysis of the response patterns as displayed in Figures 4A and 4B confirmed that Christians showed a small but significant ( $p \sim 0.001$ ) lower humour rating and Muslims and Hindus chose higher humour ratings at very significant levels $(\mathrm{p}<<0.001)$. Statistical analysis of the votes of participants who marked a joke as offensive was limited by the low number of votes for many of the categories. Only the strong decrease in funniness ratings upon feeling offended and the higher ratings seen in the Hindu populations reached statistical significance.

\subsection{Research Question 2: Does religious belief affect people's sensitivity toward irreverent (religiously offensive) jokes?}

In our selection of jokes, we tried to balance good-natured with offensive jokes and chose from topics that target specific religions. Figure 5 reflects the attitude of various study subpopulations as a function of the a-priori classification of the offensive versus witty quality of the 24 jokes. The responses confirm that the jokes span a range of funniness, depending on what population is looking at them. About one third of the jokes ( 9 jokes, see Table 2 ) were often rated offensive across a spectrum of affiliations. Another third was offensive mostly to specific affiliations, the remainder, was rarely voted as offensive. 


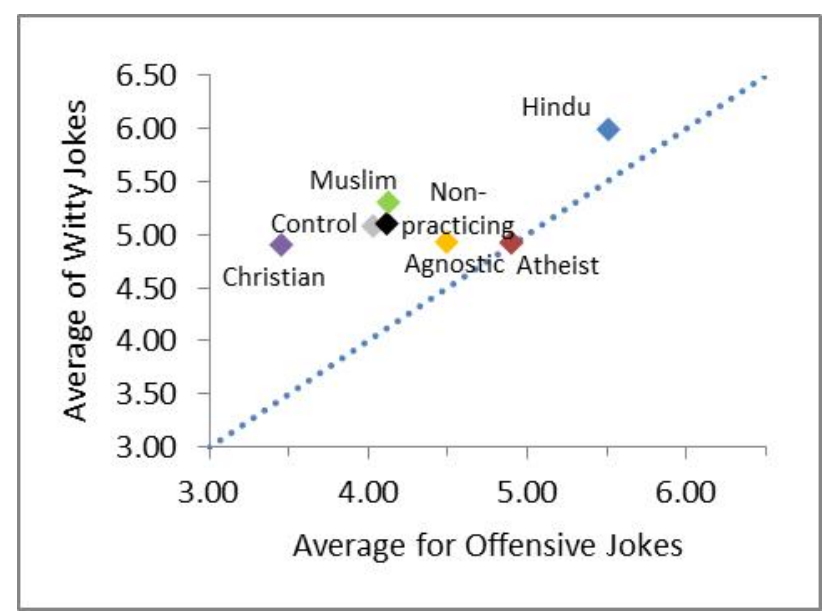

Figure 5: Average funniness rating for 9 offensive versus 15 witty jokes for each group. The blue line is the diagonal.

Christians, Atheists, and Agnostics rate witty jokes on average equally funny (4.9), Muslims rate them about $1 / 2$ unit higher (5.3), and Hindus find them more than one unit funnier (6.0). Comparing offensive and witty ratings, Atheists rate both groups equally, Agnostics and Hindus discount offensive jokes about $1 / 2$ unit and every other group has at least 1 unit lower average funniness ratings, with Christians rating offensive jokes 1.5 units lower.

In general, the fraction of offensive votes matches the authors' a-priori classification of offensive versus witty jokes (see Table 2). However, this comparison does not control for any bias in the selection of jokes. Therefore, unless otherwise stated, our analyses avoid the bias inherent in any a-priori classification of offensiveness or religious "target" affiliation, and instead we relied on the participants' own indication of being offended by certain jokes.

The degree of offensiveness varies between groups. For instance, Q07-Holocaust, is seen as the most offensive joke by Atheists and Agnostics, but is not seen as offensive by Hindus (rank 18) and it only ranks 11th (together with Q15-Real/picture Jesus) for Muslims. The top 9 offensive jokes for Atheists and Agnostics contain jokes such as Q24-Circumcised (Ranks 3 and 9) and Q22-Burkhas (ranks 6 and 8). Christians most strongly objected to Q19, Q15, Q07, Q08, Q20, Q09, i.e. all jokes either targeting Christianity or Judaism, and all nine jokes designated as "offensive" by the authors were within the top 11 ratings for them. Muslims ranked the irreverent Islam-targeting jokes as the most offensive ones (first three ranks), but they only mildly object to more good-natured Islam-targeting "witty" jokes (Q26-Leapfrog, Q03-Ramadan, and Q22-Burkhas), which received similar numbers of offensive votes from them as did jokes whose butts were Christians and Jews. The Hindus' sense of offensiveness varies most strikingly from that of the other groups: They rank jokes in the following order (ties in parenthesis): Q08-Wine into Water, Q09-Asterisk, Q11-Deer, (Q13-Weed, Q19Trinity), (Q05-Standing on Bible, Q20-One woman's affair), (Q23-Time-travel device, Q15Jesus picture).

\subsection{Research Question 3: How does the offensiveness of religious jokes affect their funniness?}

Jokes perceived as offensive were overwhelmingly considered as lacking in humour, with $56 \%$ of all "offended" responders voting "Not funny" (Figure 4B). Other response categories are "Slightly funny" (19\%) "Okay" (12\%), "Funny" (7\%), and "Hilarious" (5\%). Three quarters of the total populations chose the two lowest funniness ratings when they felt 
offended. However, being offended did not automatically translate into a categorical dislike of the joke: only $45 \%$ of Muslims rated a joke "Not funny" when they were offended, while another $45 \%$ of their responses to offensive jokes fell into the "Slightly funny" or "Okay" bin. The seemingly paradoxical tendency to be amused despite being offended was even more pronounced among the Hindus. Although they recorded the second highest number of "offensive" votes (20\% overall), Hindus rated over two thirds of the jokes they classified as offensive also as "Okay", "Funny", or "Hilarious" and chose "Not funny" only for one fifth of the jokes they found offensive. Similarly, while Muslims had most often indicated that they considered a joke offensive ( $24 \%$ or 281 votes, Figure 1 , red line), they were still giving higher ratings to those jokes than most other participants. Atheists, who rarely $(4 \%$, or 68 votes) found a joke offensive, rated those jokes less negatively and chose more often "Slightly funny" rather than "Not funny". Most strongly opposed to offensive jokes were Non-practicing, Agnostics and Christians, two fifth of whom rated a joke "Not funny" or "Slightly funny" when they were offended by it.

There is a correlation by which jokes that have high numbers of offensive ratings also draw more disagreement about their funniness when comparing the response from different study groups. In contrast, the jokes drawing the lowest numbers of "offensive" votes (i.e. the witty, non-religious jokes) elicit little disagreement among the groups, and they receive consistently higher funniness ratings across all religious sup-populations.

\subsection{Research Question 4: Do people rate the funniness of offensive jokes targeting their own religion differently from jokes targeting other religions?}

To address the relationship between religious affiliation and sensitivity toward offensive joke material in greater detail, we selected the three most offensive jokes targeting specifically Christians ("C3", i.e. Q20-One woman's affair, Q08-Wine into Water, Q15-Real/picture Jesus) and the three most offensive jokes targeting Muslims, ("M3", i.e. Q23-Time-travel device, Q13-Weed, Q17-Islam Tolerant). Thus, we have two sets of jokes that provide us with a "level playing field" for such a comparison: both sets offer similar funniness levels, with all participants rating set C3 and M3 at 4.4 and 4.5 funniness units, respectively, and both groups finding the jokes attacking the other religion quite funny (4.3 funniness units), while jokes against their own religion are "punished" with a reduction of funniness by 1 unit (Christians) and 0.6 units (Muslims).

\begin{tabular}{lccccc} 
Series & $\begin{array}{c}\text { Christians } \\
\text { offended }\end{array}$ & $\begin{array}{c}\text { Muslims } \\
\text { offended }\end{array}$ & $\begin{array}{c}\text { Christians } \\
\text { funniness }\end{array}$ & $\begin{array}{c}\text { Muslims } \\
\text { funniness }\end{array}$ & $\begin{array}{c}\text { All } \\
\text { funniness }\end{array}$ \\
\hline C3 & $44 \%$ & $28 \%$ & 3.3 & 4.3 & 4.4 \\
M3 & $15 \%$ & $47 \%$ & 4.3 & 3.7 & 4.5
\end{tabular}

Table 3: Pairwise comparison of the reactions of Christians and Muslims to three highly offensive jokes targeting Christianity (C3=[Q20,Q08,Q15]) versus three highly offensive jokes targeting Muslims (M3=[Q23,Q13,Q17]).

Each set is judged offensive by $44 \%$ and $47 \%$ of the respective targeted religion's followers, but only $15 \%$ of Christians find the jokes attacking the other religion to be offensive to them while the percentage of Muslims offended by Christianity-targeting jokes is almost double 
that (28\%). It appears that while Muslims and Christians are equally likely to take offense at jokes targeting their religion, Muslims do not react as strongly as Christians do to them, i.e. the Muslims' funniness reduction for jokes of which they are the butt is less pronounced.

\subsection{Evaluation of bias, confounding, and other methodological considerations}

As part of the preparation for our analysis, we employed uncensored method such as Principal Component Analysis and Partial Least Square Analysis to determine if any of the demographic categories, alone or in combination, would subset the data. We found only two significant Principal Components which closely aligned with offensiveness followed by funniness. Religious groups were the major determinants explaining the variation in the data, and no other demographic factor added significantly to explain the (remaining) variance. It should be emphasised that this only allows us to state that secondary factors do not confound this analysis. It does not mean that those factors were sampled in a representative manner or that they could not be a factor to humour appreciation. The population sampled is too homogenous - largely a population of more liberally leaning, less than 40-year olds - to influence the result. Christians in this study were more conservative, but adding conservatism as a cofactor did not explain the lower humour ratings of Christians.

In addition to screening for possible bias, we also tried to work around using averages as a descriptor of population responses, because averages can easily hide subsets of respondents within each group. Instead, we treated the responses as ordered probabilistic phenomena and allowed for multimodal response patterns.

Geographically, the vast majority of the survey participants live in the United States, with two exceptions: $97 \%$ of Hindus reported from India, and the Muslims were almost evenly split between India and the United States. Therefore, analysis of the Muslim data needs to be mindful of the possible confounding of religion and religious group identification. Participants reporting from Europe and other regions constituted negligible numbers. However, somewhat surprisingly, we did not find that Muslims from India and from the US show significant differences in their responses, with the exception of the response to Q4Baby Oil, ( $\mathrm{p}=0.0014$, by t-test).

Although not entirely homogenous, our sample population is demographically compact, with moderate possibility of confounding due to disparities in age, ideology, and region. Our extensive analysis of possible confounding factors (via PCA, PLS, ANOVA) did indeed not indicate bias with respect to any of the demographic factors in pairwise comparisons (other than the unresolvable confounding of the Hindu religion and India). Even the Muslim population that was geographically split did not segregate along that border. Similarly, the gender ratio did not differ much among the groups, and, when summarised over all 24 jokes, gender did not significantly affect the responses.

One caveat concerns the size of our samples. While the overall number of participants is quite high $(\mathrm{N}=783)$, some of the subgroups, notably the Hindu (52) and Muslim (57) populations, are not very large (which is mainly due to the difficulty of recruiting participants among those populations). Still, their size is well within the common norm for quantitative humour appreciation studies (e.g. Cunningham \& Derks 2005; Martin et al. 2008). ${ }^{7}$ In fact, some empirical studies (e.g. Wilson 1990; Braun \& Preiser 2013) operate with significantly smaller sub-populations. ${ }^{8}$ We guard against over-interpretation and undue generalisation by a full statistical analysis and with multiple independent measures, i.e., multiple jokes in each category.

Our study employs macro denominational religious labels that have the benefit of sociocultural consensus behind them (Alwin et al. 2006). For both conceptual and practical, statistical considerations, we avoided dissecting each religion into different religious 
subcategories like "Lutheran" or "Roman Catholic," and we steered clear of inherently ambivalent (Alwin et al. 2006) movement subdivisions such as "Mainline Protestant" or "None". The jokes on our survey engaged with Islam, Christianity, and Judaism in general, not with any particular subgroup. Generic religious labels were further indispensable for our purpose because we address common perceptions - and prejudices-about religion and humour, which operate on the macro-level of generic identity categories.

Our menu of generic religious self-identification categories does not imply that we believe people are wholly defined by such macro-categories. People's identity positioning depends on context, and it is fluid, with various identity markers becoming more or less dominant in different discursive and social situations (Davies \& Harré 1990; Hall 1996). In the context of our survey, participants responded to the religious identity label that properly hailed them (Althusser 1971). The shape of our data directly validates our choice of such religious categories. For instance, by looking at a graphic representation of the answer options elicited from jokes aimed at Christians and Muslims, we can clearly tell who is doing the voting (Figure 6).

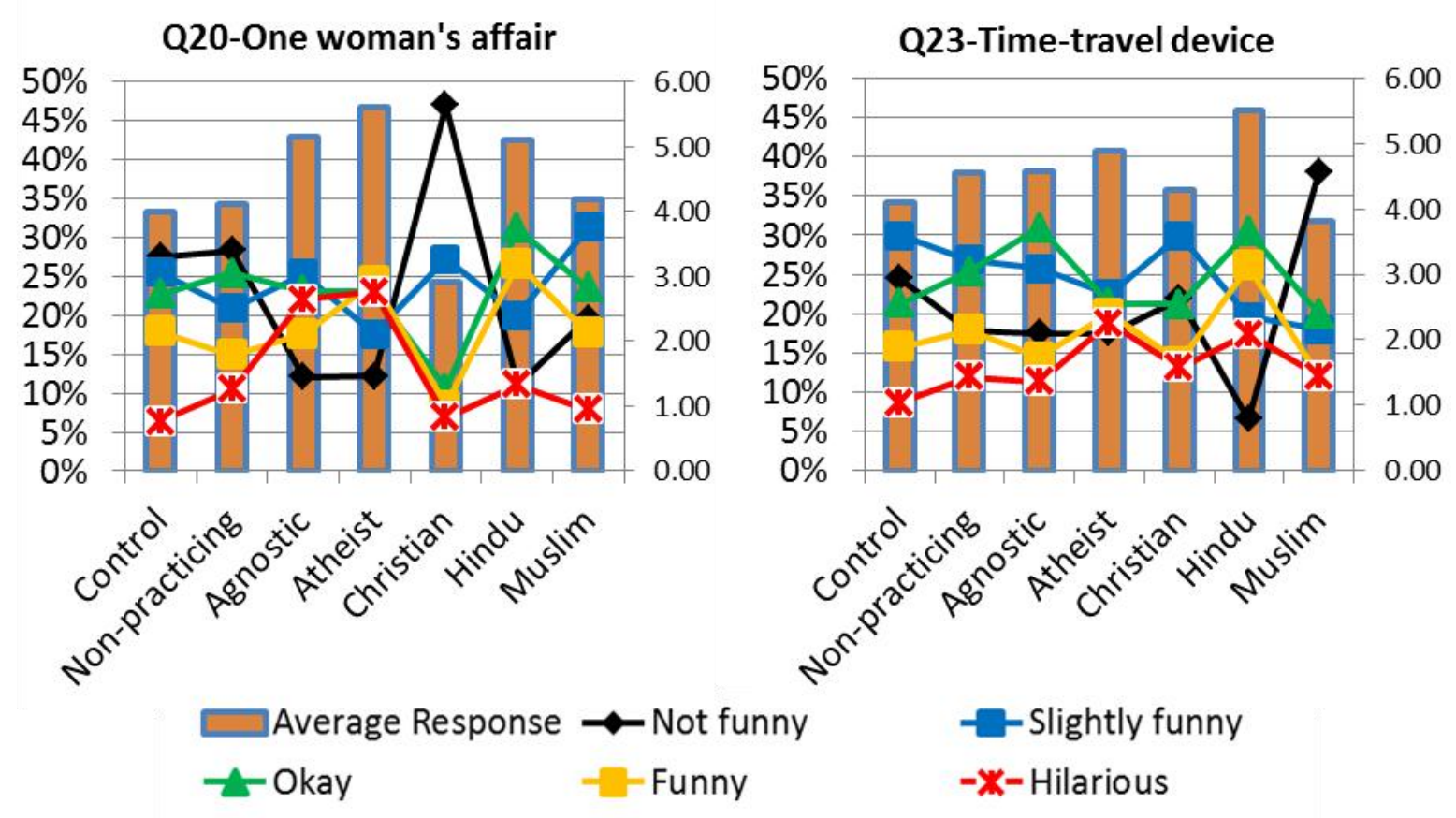

Figure 6: Frequency (left axis) with which the different response categories were chosen by each group (lines color-coded as indicated) and average responses per group (bars, right axis) for "One Woman's affair" (6A), a blasphemous joke targeting Christianity; and "Time-travel device" (6B), an irreverent joke targeting the Koran.

Figure 6A compares the answer patterns of the groups to highly blasphemous jokes directed against Christianity and Islam, respectively. Almost 50\% of Christians voted "not funny" to the joke targeting a central Christian dogma, but only 20\% of Muslims found the same joke to be "not funny". Conversely, when judging an irreverent joke whose butt was Islam (Figure 6B), almost 40\% of Muslims voted that this joke as "not funny", while Christians shared this negative assessment only about half as frequently. Hence, the voting pattern of each group is 
consistent with its members' macro-denominational self-identification, notwithstanding other sub-denominational affiliations that these respondents may also hold.

\section{Discussion}

We present an extensive empirical survey that evaluates how the cultural setting of a religious belief affects humour and in particular the response to religious and irreverent jokes. Our data indicate that being religious is not generally negatively correlated with people's sense of humour. This contradicts the findings of earlier research by Saroglou \& Jaspard (2001) and Saroglou (2002), who had argued that religiosity is negatively correlated with sense of humour. In 2001, Saroglou \& Jaspard (2001: 33) reported that "religious stimulation inhibited humour" and one year later, Saroglou (2002: 205) argued that "from a psychological, and especially from a personality psychology perspective, religion associates negatively with personality traits, cognitive structures and social consequences typical to humour". While our data leads us to reject such generalisations, we did find that religious self-classification had a measurable and statistically significant impact on the quality of humour appreciation. Notably, Hindus show greater enthusiasm toward all the jokes on the survey than any other group, while Christians rated the jokes slightly, but significantly lower than a mixed control population. Muslim results show a robust enjoyment of jokes, including religious ones, and by some measures the Muslims' humour appreciation exceeded that of other groups. This latter result has to be qualified by the fact that the Muslim sample was skewed by age $(95 \%$ 20-39 years old) and tracked ideologically liberal (60\%).

Regardless of the participant's religious affiliation and regardless of the joke's subject matter, being offended by a joke strongly diminished the funniness and appreciation of that joke. The reaction to jokes deemed offensive was by far the strongest determinant of humour reaction. Across all study groups, being offended by a joke significantly lowered the funniness of that joke, and those participants that rate a joke offensive most likely do not find any funniness in it. Jokes targeting one's own religion consistently rank highest in the count of "offensive" votes among Christians and Muslims.

The "superiority theory" of humour suggests that people react more favourably to jokes that target rival groups. This has been confirmed in political humour, where liberals were found to prefer jokes directed at conservatives, and vice versa (Braun \& Preiser 2013). Another study based on gender-specific humour (Abrams et al. 2015) found that women rated jokes targeting men as funnier than those targeting women, and vice versa for men. We observed a similar effect for Atheists who enjoy religious offensive jokes in particular. However, jokes aimed at other faiths did not generally create high enthusiasm in believers. Both Muslims and Christians were not amused by jokes attacking the other religion, and they gave even lower funniness ratings to offensive jokes aimed at their own religion (Table 3). Interestingly, a higher proportion of Muslims took offense at irreverent jokes targeting the other religion than Christians did, suggesting that it matters somewhat less to Muslims what religion is offended as long as there is an element of offensiveness in the religious joke.

The non-religious control jokes as a class were deemed more funny in the aggregate by all participants of the survey compared to the religious jokes. Only one religious joke (Q24Circumcision) featured among the top 6 funniest jokes, as measured by average funniness ratings (Table 2). Whether religious jokes are generally less funny than non-religious ones is difficult to answer definitively, as we do not have a way of matching jokes objectively, but the reaction of Non-practicing believers, Atheists, and Agnostics to religious versus nonreligious jokes indicates that this is the case. Together with the sensitivities of religious 
individuals, and the possibility of a religious joke not being understood by many, it can be concluded that choosing religious themes will risk lowering such jokes' broad appeal.

Christians were the group with the least favourable humour ratings toward the 24 jokes on the survey (see Fig. 1). Even when not offended, they chose "slightly funny" most often and they also have the highest proportion of "Not funny" ratings (Fig 4A). Yet, the Christian participants of our survey were not demonstrating a congenital lack of humour. Their reaction to non-offensive humour equalled that of, e.g., Atheists and a proportion of them voted even blasphemous jokes to be "funny" or "hilarious". But in comparison with other groups, Christian participants as a group demonstrated modestly significantly lower humour ratings even after individual offensiveness ratings were considered. The lower funniness ratings of Christians may be attributable to cultural reasons. As indicated in the introduction, Church authorities have preached for many centuries that laughter was sinful and quite literally the work of the devil (Arbuckle 2008: xiii). As one scholar sums it up:

There are two reasons for opposing laughter: it distracts the devout from their contemplation of God and there is no good reason to laugh. ... Not just the Benedictines but even the Franciscans and all other orders and congregations generally regard laughter as sinful while mournful tears are cultivated as true devotion.

(Geybels, 2011, 14)

This study indicates that Christians are not much imprinted by this history when nonreligious humour is presented. Offensive religious jokes, however, are most strongly objected to by Christians.

Based on data obtained from our sample of (mostly young and liberal) Muslims, the perception that Islam generally predisposes its followers against humour must be qualified and largely rejected: considering all answers, the average funniness rating of the Muslims is similar to Non-practicing, Atheists, and Agnostics, and it surpasses Christians. Compared to Hindus, Muslims tend to avoid the highest funniness rating ("Hilarious"), and produce more moderate ratings ("Okay", "Funny"), possibly in line with the teaching of Islam regarding moderate expressions of amusement (Marzolph 2012: 175). The common (Western) perception that Muslims are quite easily offended by religious comedy is supported by a high fraction of Muslim respondents finding certain jokes offensive. Interestingly, Muslims' sense of offensiveness is not limited to jokes specifically targeting Islam but extends to some degree to jokes aimed at deities and beliefs of other religions. Nevertheless, this does not imply that our Muslim survey takers cannot take a joke. When we compare only responses not marked as offensive to participants, Muslims rank second highest at finding jokes funny, surpassed only by Hindus; and even when offended, the Muslims' responses are not as negative as those of other groups who were offended. About one half each of the Muslims resided in India and North America. In their answer patterns, those two subsets (American and Indian Muslims) were largely undistinguishable, which argues against confounding by cultural identification. These results contradict the common (Western) perception and generalisation that militant actions against mockers of Islam and violent street protests against cartoons are indicative of a shared negative attitude to humour among all Muslims.

Our study demonstrates that religious affiliation can have a measurable and statistically significant impact on the quality of humour appreciation in certain groups. Altogether, the Hindus' average funniness rating across all 24 jokes was about one unit higher than that of all other groups. While Hindus were not specifically targeted in any of the jokes the higher ratings are equally observed for the subset of non-religious jokes, indicating that the Hindus' high humour ratings are not related to the targeting. Moreover, Hindus rate jokes more often as offensive but may still enjoy such offensive jokes. We can speculate that Hindu culture is conditioned to be well disposed toward all kinds of humour, including irreverent religious 
jokes: "Generally, mockery and worship go together. . . . Ordinary Hindus . . . don't mind acknowledging the lighter side and taking a laugh at the same gods whom on other occasions they sincerely venerate" (Elst 2011: 37). Morreall (1999) and Siegel (1987) have similarly argued that Hindu culture has evolved a positive evaluation of humour in religious contexts, viewing it tolerantly and historically encouraging satire that targets saints, priests, and even the gods.

As indicated above (section 4.2.), the analysis of our data allowed us to replicate our earlier study that compared the humour appreciation between Christians and Atheists (Schweizer \& Ott: 2016). This is even more noteworthy because the mode of recruiting participants (a college-centred social media outreach in the 2016 study versus MTurk here) and the type of jokes (complex literary passages versus simple jokes and cartoons) was very different. Yet those different representatives and the different genres of humour still demonstrated that religious affiliation is a key driver when rating religious jokes. This replication is yet another indication that we have avoided confounding the results with socioeconomic factors. Again, this does not mean that other factors are not relevant to humour perception; it only shows that we have successfully avoided biasing our survey with such cofactors, largely by having those factors represented roughly evenly in our side-by-side comparisons, i.e., the relative differences in the responses of the various religious groups are largely determined by the religious affiliation.

It is important to reiterate that not all populations in this study were themselves directly targeted by jokes on the survey. Specifically, none of the jokes were directly aimed at Hindus, Agnostics, or Atheists (the 18 jokes with religious subject matter targeted Christians, Jews, and Muslims). Interestingly, only one of the three non-targeted groups (the Hindus) recorded a significantly higher overall average rating for all jokes, while only one of the two targeted groups (the Christians) posted a significantly lower aggregated funniness average for all jokes. Thus, whether a group was targeted or not did not predict a generally more or less favourable reaction to the joke-corpus as a whole. Religious practice and belief, however, markedly determined the response to individual jokes.

When it comes to the reaction to religious humour, and in particular to offensive religious humour, religious affiliation appears to be the most important determinant, more important than gender, age, income, political ideology, and geographic location. Indeed, the iteration over all combinations of possible confounding factors and our attempts to identify subpopulations within the larger groups (e.g. Christians) did not reveal factors that would produce better models. Although the study is skewed toward younger, more liberal participants, none of the other demographic factors, when introduced into the statistical model, yielded significant contributions.

\section{Conclusion}

This empirical study of almost 800 mostly younger participants, focusing on practicing Christians, Hindus, Muslims, as well as on Atheists and Agnostics evaluates humour appreciation in relation to religious affiliation and specifically studies the response to offensive religious jokes. The evidence provides that religious belief affects the response to religious, but not to non-religious jokes. Religious belief does not prevent people from appreciating humour, not even if this humour is religious in nature, but religion strongly affects how the offensiveness of jokes is experienced.

The Hindu population is predisposed to find different kinds of jokes funnier than all other groups. We refute the perception that all Muslims are predisposed against humour. Christians show a reduced appreciation of the jokes compared to all other groups. 
Being targeted as a group by a joke most likely reduces the joke's funniness for that group and jokes that are perceived as personally offensive will not be appreciated and in many instances lead to a total dislike of that joke. The aversion to offensive jokes is most pronounced with Christians and least evident with Hindus. Muslims and Hindus are most likely to rate a joke as offensive, even those that target other religious groups. However, this does not prevent Hindus from rating many offensive jokes still as funny. Jokes targeting other religions are also appreciated less by believers of the various other faiths. By contrast, Atheists in particular, but not Agnostics and Non-practitioners, enjoy the religiously offensive jokes.

\section{Notes}

1 "Neutral" or "N/A" is a judgment outside of our rating scale. Participants who felt that a given joke was irrelevant to humour could leave the answer blank.

${ }^{2}$ We chose a pseudo-continuous scale as a compromise between the desire to have a continuous scale and user experience concerns. User interfaces using sliders are difficult to manipulate, especially on a small smartphone.

${ }^{3}$ Retroactively combining the three sceptical categories (Agnostics, Atheists, and Nonpracticing believers) into a category of "Nones" would have entailed a reduction in statistical sensitivity and introduced bias by hindsight.

${ }^{4}$ Matrices of all pairwise comparisons between all groups have been prepared and are available upon request. They were used in preparation of the analysis, and in the evaluation of possible cofactors.

${ }^{5}$ Setting a cap to stop recording returns from certain populations after reaching a given number was rejected as impractical. Setting a cap is one thing, actually reaching it another (e.g. only 2 of 6 groups reached 100 participants). Moreover, quality filters to eliminate bad surveys affect different groups differently, resulting in unequal groups sizes.

6254 returns lacked religious self-identification information ("N/A"). This provided us with an independent reference population composed of random numbers of members of all religious and non-religious groups.

${ }^{7}$ Martin et al.'s (2008) study draws on population sizes of 51, 52, and 52.

${ }^{8}$ Wilson (1990) operates with conservative and liberal sub-populations of 30 participants each. 


\section{Appendices}

\section{Appendix A}

\section{FAITH AND HUMOR--A SURVEY}

Please record your reaction to a number of jokes and cartoons below. Some of these jokes may come across as offensive or in bad taste, but opinions differ and we want to know what you think. The point is not to offend anybody wilfully but to find out what is and is not considered funny or offensive by members of different religious traditions and by non-religious people.

Q2: "There was a very gracious lady who was mailing an old family Bible to her brother in another part of the country. 'Is there anything breakable in here?' asked the postal clerk. 'Only the Ten Commandments,' answered the lady."

Q3: Ramadan: Putting the slim back into Muslim.

Q4: Image: "If olive oil is made from olives, what is baby oil made of? OMG!" A baby with a shocked look on its face.

Q5: A young boy was found standing on a Bible and when asked why he did this, he answered "today in Church our pastor told us to stand firm on the word of God."

Q6: What did the grape say when it got stepped on? Nothing--but it let out a little wine.

Q7: Q: Why did God not help the Jews during the Holocaust? A: He was too busy filming scenes for the History Channel.

Q8: Image: "Jesus turns wine into water..." Jesus peeing over a cliff, empty wine bottles at his feet.

Q9: THOU

Moses to God: Why

SHALT

NOT

KILL*

God: Well,

$\begin{array}{cc}\text { is } & \text { there } \\ \text { that's } & \text { for }\end{array}$

asterisk?

Moses: Exceptions!?

God: $\quad$ Yes, you know, the Amelekites, the Hittites, the Emorites, the Jebusites...

Moses: But....

God: $\quad$ Kill all the motherfuckers, is that so hard to understand!?

Q11: A man kills a deer and takes it home to cook for dinner. Both he and his wife decide that they won't tell the kids what kind of meat it is, but will give them a clue and let them guess. The dad said, "Well it's what Mommy calls me sometimes." The little girl screamed to her brother, "Don't eat it! It's an asshole!"

Q12: Image: "Work in mysterious ways / Mysteriously similar to random chance." A meme.

Q13: I call my weed the Quran because burning that $\mathrm{s}^{* * t}$ will get you stoned.

Q14: Math attentiveness question

Q15: Q: What's the difference between real Jesus and a picture of Jesus? A: It only takes one nail to hang up the picture.

Q16: Is one permitted to ride in an airplane on the Sabbath? Yes, as long as your seat belt remains fastened. In this case, it is considered that you are not riding, you are wearing the plane.

Q17: Image: "Islam is a tolerant religion! We tolerate fanatics, suicide bombers, terrorist 'charities'... and women...barely." An overweight Muslim cleric shouts this declaration.

Q18: Q: How did you get out of Iraq? A: Iran

Q19: Image (Source: Charlie Hebdo): "The Father"; "The Son"; "The Holy Ghost." Grotesque drawing showing the persons of the Trinity engaging in a sex act. 
Q20: Christianity: "One woman's lie about having an affair that got seriously out of hand."

Q21: I went to the doctor's the other day and said, 'Have you got anything for wind?' So, he gave me a kite.

Q22: Image: "The one on the left is hot." Showing three women completely covered up in blue burkas. A meme.

Q23: Arab scientists have invented a time-travel device that can transport an entire country back to the middle ages. They're calling it "Islam".

Q24: Why do Jewish men have to be circumcised? Because a Jewish women won't touch anything unless it's $10 \%$ off.

Q25: Image: "Dad it's so cold in here." "Go stand in the corner." "Why?" "The corner is 90 degrees." Cartoon showing exchange between father and son.

Q26: Isn't it tough if you're in a Mosque during prayer time....and you really enjoy leapfrog?

Q27: Image: "After $39 \frac{1}{2}$ years of wandering in the desert, Mrs. Moses secretly asks for directions," while Moses hollers "This way! Follow me!"

Ramadan: Putting the slim back into Muslim.

\begin{tabular}{|c|c|c|c|c|c|c|c|}
\hline & \multicolumn{3}{|r|}{ Funniness } & \multicolumn{2}{|c|}{ Offensiveness } & \multicolumn{2}{|r|}{ Comprehension } \\
\hline & $\begin{array}{l}\text { Not } \\
\text { funny }\end{array}$ & $\begin{array}{c}\text { Slightly } \\
\text {... funny }\end{array}$ & ... Okay ... Funny ... Hilarious & $\begin{array}{l}\text { Offensive to } \\
\text { me }\end{array}$ & $\begin{array}{l}\text { Not offensive } \\
\text { to me }\end{array}$ & $\begin{array}{l}\text { Igot } \\
\text { this } \\
\text { joke }\end{array}$ & $\begin{array}{l}\text { Had to I did not get } \\
\text { think this joke }\end{array}$ \\
\hline · & & 00 & 000000 & 0 & 0 & 0 & 0 \\
\hline
\end{tabular}

Survey layout for each joke.

\section{Appendix B}

Tabulation of survey results. The number of respondents is tabulated in rows for each Question (Qnum) separated by individual responses as to the offensiveness of the question (Offence). The respondents are grouped by religious self-identification. The counts are enumerated for each response (1 (not funny)-9 (Hilarious), and empty (NA). For each religions group the number of participants and the number of individual answers excluded as "not understood" are also given. 


\begin{tabular}{|c|c|c|c|c|c|c|c|c|c|c|c|c|c|c|c|c|c|c|c|c|c|c|c|c|c|c|c|c|c|c|c|c|c|c|c|c|c|c|c|c|c|c|c|c|}
\hline \multicolumn{2}{|c|}{ Response Counts } & \multicolumn{11}{|c|}{$\begin{array}{l}\text { Control } \\
269 \text { Participants NA=(61) }\end{array}$} & & & $2 \mathrm{~Pa}$ & $\begin{array}{l}\text { Jon } \\
\text { rtic }\end{array}$ & ipa & ats & ing & $=(17)$ & & & & & & $00 \mathrm{~Pa}$ & $\begin{array}{r}\mathrm{Ag} \\
\text { artic }\end{array}$ & gnos & $\begin{array}{l}\text { stic } \\
\text { nts }\end{array}$ & $N A=$ & $=(28)$ & & & & & & $0 \mathrm{Par}$ & $\begin{array}{r}\text { At } \\
\text { rticip }\end{array}$ & $\begin{array}{l}\text { theis } \\
\text { pant }\end{array}$ & ist & $\sqrt{A}=12$ & & & \\
\hline Offence & Qnum & NA & 1 & 2 & 3 & 4 & 5 & & & & 8 & 9 & NA & 1 & 2 & 3 & 4 & 5 & 6 & 7 & 8 & 9 & & NA & 1 & 2 & 3 & & 5 & 6 & 7 & & 9 & N & & 1 & 2 & & & & & & & \\
\hline No & 202 & 1 & 14 & 17 & 35 & 5 & 40 & & 338 & 86 & 17 & 8 & 0 & 2 & 8 & 13 & 1 & 16 & 9 & $\begin{array}{ll}9 & 12\end{array}$ & & 6 & 3 & 0 & 6 & 9 & 18 & & 24 & 10 & 24 & 5 & 3 & & 0 & 10 & 8 & 12 & 31 & 14 & 4 & 19 & 3 & \\
\hline No & 0.03 & 0 & 20 & 16 & 37 & 6 & 43 & & 74 & 42 & 20 & 11 & 0 & 8 & 3 & 7 & 0 & 10 & 5 & 513 & & 4 & 2 & 0 & 8 & 10 & 12 & 4 & 15 & 9 & 17 & 6 & 1 & & 1 & 9 & 4 & 11 & 4 & 6 & 4 & 20 & 5 & \\
\hline No & Q04 & 0 & 15 & 9 & 25 & 13 & 39 & & 98 & 83 & 26 & 31 & 0 & 2 & 5 & 6 & 1 & 4 & 5 & 521 & 110 & & 8 & 0 & 9 & 8 & 11 & 6 & 19 & 13 & 27 & 5 & 2 & & 0 & 7 & 5 & 15 & 41 & 11 & 9 & 10 & 10 & \\
\hline No & 05 & 2 & 33 & 22 & 32 & 12 & 54 & & 353 & 38 & 16 & 11 & 0 & 3 & 10 & 9 & 2 & 20 & 8 & 39 & & 5 & 3 & 0 & 19 & 13 & 16 & 4 & 25 & 6 & 11 & 4 & 0 & & & & 13 & 9 & 21 & 14 & & 7 & 6 & \\
\hline No & 106 & 2 & 9 & 17 & 34 & 13 & 49 & & 126 & 63 & 27 & 9 & 0 & 6 & & 11 & 1 & 10 & 10 & 21 & & 6 & 2 & 0 & 2 & 9 & 14 & 8 & 18 & 14 & 26 & 5 & 3 & & 1 & 3 & & 19 & 41 & 11 & 8 & 18 & 6 & \\
\hline No & 0.07 & 0 & 28 & 24 & 18 & 12 & 24 & & 23 & 36 & 10 & 4 & 0 & 10 & 8 & 7 & 1 & 10 & & 26 & & 3 & 4 & 0 & 20 & 11 & 2 & 6 & 4 & 7 & 6 & 7 & 2 & & 0 & 15 & 4 & & 4 & 8 & 2 & 12 & 3 & \\
\hline No & 208 & 0 & 17 & 20 & 22 & 13 & 26 & & 75 & 53 & 18 & 8 & 0 & 5 & 5 & 5 & 1 & 10 & & $4 \quad 13$ & & 5 & 6 & 0 & 21 & 4 & 8 & 3 & 10 & 9 & 27 & 9 & 1 & & 0 & 9 & 4 & 12 & 51 & 15 & 6 & 14 & 5 & \\
\hline No & 09 & 0 & 32 & 17 & 23 & 11 & 21 & & 82 & 27 & 14 & 12 & 0 & 8 & 6 & 7 & 3 & 5 & 2 & 211 & & 2 & 5 & 0 & 18 & 3 & 5 & 6 & 10 & 5 & 21 & 8 & 7 & & 0 & 8 & 7 & & 4 & & 5 & 13 & 10 & 10 \\
\hline No & Q11 & 0 & 7 & 4 & 18 & 4 & 13 & & 78 & 86 & 44 & 55 & 1 & 0 & 2 & 1 & 3 & 6 & 1 & 124 & 412 & 21 & 7 & 0 & 4 & 3 & 9 & 3 & 6 & 11 & 32 & 14 & 16 & & 0 & 3 & 2 & 6 & 1 & & 13 & 20 & 12 & 14 \\
\hline No & $\mathrm{Q} 12$ & 0 & 41 & 23 & 23 & 10 & 39 & & 64 & 47 & 14 & 5 & 0 & 11 & 8 & 6 & 3 & 14 & 5 & 57 & 75 & 5 & 1 & 0 & 12 & 9 & 5 & 5 & 15 & 7 & 18 & 16 & 6 & & 0 & 5 & 4 & & 3 & 8 & 4 & 23 & 14 & 10 \\
\hline No & Q13 & 0 & 31 & 13 & 22 & 13 & 31 & & 4 & 45 & 24 & 27 & 0 & 9 & 4 & 3 & 4 & 6 & & $\begin{array}{lll}3 & 14\end{array}$ & & 6 & 7 & 0 & 6 & 4 & 8 & 4 & 17 & 9 & 24 & 10 & 10 & & 2 & 7 & 1 & & 3 & 9 & 8 & 18 & 13 & \\
\hline No & 215 & 0 & 17 & 19 & 16 & 8 & 33 & & 3 & 34 & 16 & 24 & 0 & 5 & 4 & 1 & 2 & 12 & & $\begin{array}{lll}310\end{array}$ & & 6 & 5 & 0 & 14 & 7 & 7 & 3 & 12 & 6 & 24 & 8 & 7 & & 1 & 10 & 5 & & 31 & 13 & 6 & 15 & & \\
\hline No & 16 & 0 & 52 & 20 & 26 & 4 & 28 & 2 & 253 & 38 & 10 & 4 & 0 & 16 & 8 & 9 & 1 & 5 & 5 & 5 & & 2 & 0 & 1 & 18 & 6 & 11 & 2 & 16 & 4 & 11 & 6 & 0 & & 0 & 20 & 7 & 8 & 11 & 11 & 5 & 6 & 2 & \\
\hline No & Q17 & 0 & 37 & 34 & 23 & 5 & 40 & & 202 & 27 & 11 & 12 & 0 & 10 & 6 & 9 & 7 & 8 & 6 & 55 & & 5 & 2 & 1 & 12 & 9 & 13 & 5 & 15 & 8 & 11 & 4 & 7 & & 0 & 14 & 4 & 7 & 21 & 15 & 8 & 10 & 7 & 3 \\
\hline No & Q18 & 0 & 23 & 17 & 27 & 11 & 40 & & 46 & 69 & 26 & 18 & 0 & 4 & 4 & & 3 & 20 & 4 & $\begin{array}{l}4 \quad 17 \\
\end{array}$ & & 5 & 6 & 0 & 6 & 10 & 15 & 4 & 19 & 9 & 20 & 7 & 5 & & 0 & 10 & 6 & 14 & 11 & 11 & 8 & 9 & 9 & 10 \\
\hline No & Q19 & 0 & 37 & 15 & 12 & 5 & 13 & & 31 & 11 & 4 & 7 & 0 & 11 & 1 & 4 & 1 & 5 & 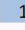 & 13 & 3 & 1 & 4 & 0 & 19 & 6 & 5 & 2 & 10 & 1 & 4 & 2 & 5 & & 0 & 15 & 7 & 4 & 3 & 6 & 3 & 2 & 2 & 5 \\
\hline No & Q20 & 1 & 32 & 14 & 32 & 8 & 39 & - & 54 & 43 & 6 & 10 & 0 & 13 & 6 & 5 & 1 & 11 & 5 & 510 & & 2 & 4 & 2 & 9 & 4 & 13 & 5 & 11 & 10 & 16 & 10 & 10 & & 0 & 8 & 2 & 8 & 3 & & 10 & 18 & 9 & \\
\hline No & Q21 & 2 & 38 & 24 & 49 & 14 & 40 & & 203 & 38 & 7 & 3 & 0 & 12 & 11 & & 5 & 10 & 4 & 47 & & 3 & 4 & 0 & 17 & 17 & 10 & 6 & 18 & 9 & 13 & 2 & 0 & & 0 & 20 & 10 & 12 & 4 & & 6 & 9 & 5 & \\
\hline No & Q.22 & 1 & 41 & 26 & 29 & 6 & 28 & & 5 & 55 & 11 & 19 & 0 & 10 & 3 & 6 & 0 & 11 & 5 & 512 & & 6 & 6 & 0 & 19 & 5 & 8 & 5 & 13 & 6 & 25 & 4 & 6 & & 0 & 17 & 4 & 6 & 3 & 8 & 7 & 19 & 6 & \\
\hline No & 223 & 0 & 45 & 20 & 35 & 13 & 30 & & 33 & 39 & 12 & 8 & 0 & 7 & 4 & 11 & 1 & 10 & 6 & 512 & & 4 & 4 & 0 & 10 & 4 & 15 & 4 & 23 & 6 & 14 & 2 & 9 & & 0 & 13 & 6 & 8 & 31 & 13 & 4 & 16 & 10 & \\
\hline No & 0.24 & 0 & 21 & 7 & 28 & 10 & 33 & 2 & 255 & 58 & 24 & 36 & 0 & 3 & 2 & 11 & 0 & 8 & 7 & 712 & & 71 & 13 & 0 & 3 & 3 & 11 & 6 & 14 & 9 & 21 & 10 & 16 & & 0 & 7 & 6 & & 4 & 5 & 1 & 19 & 10 & 13 \\
\hline No & 025 & 0 & 30 & 13 & 21 & 10 & 45 & & 256 & 63 & 25 & 17 & 0 & 6 & 9 & 6 & 4 & 10 & 6 & $\begin{array}{lll}515\end{array}$ & & 5 & 5 & 0 & 8 & 3 & 11 & 1 & 21 & 14 & 28 & 7 & 3 & & 2 & 9 & 6 & 4 & 21 & 13 & 9 & 15 & 6 & I \\
\hline No & Q226 & 1 & 29 & 20 & 32 & 12 & 37 & & 13 & 36 & 15 & 11 & 0 & 14 & 4 & 6 & 2 & 8 & 3 & $\begin{array}{lll}310 & 10\end{array}$ & & 5 & 2 & 0 & 11 & 10 & 19 & 6 & 7 & 11 & 17 & 3 & 2 & & 0 & 13 & 7 & 10 & 4 & 7 & 14 & 10 & 3 & \\
\hline No & Q27 & 1 & 30 & 15 & 36 & 9 & 39 & & 16 & 60 & 21 & 11 & 0 & 9 & 4 & 6 & 2 & 16 & 3 & $\begin{array}{l}320 \\
\end{array}$ & & 5 & 4 & 0 & 8 & 5 & 12 & 4 & 19 & 8 & 23 & 11 & 5 & & 0 & 9 & 8 & 9 & 31 & 11 & 4 & 17 & 10 & \\
\hline Yes & 0,02 & 1 & 5 & 0 & 0 & 0 & 1 & & 0 & 2 & 0 & 0 & 0 & 1 & 0 & 0 & 0 & & 0 & 3 & & 0 & 0 & 0 & 0 & 0 & 0 & 0 & 1 & 0 & 0 & 0 & 0 & & 0 & 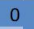 & 0 & & 0 & 1 & 0 & 0 & 0 & \\
\hline Yes & 003 & 1 & 4 & 3 & 1 & 0 & 1 & & 0 & 4 & 0 & 1 & 0 & 1 & 2 & & 0 & 1 & 0 & 0 & 00 & 0 & 0 & 0 & 1 & 0 & 0 & 0 & 2 & 0 & 0 & 0 & 0 & & 0 & 1 & 0 & & 1 & 0 & 0 & 0 & 0 & \\
\hline Yes & $\mathrm{Q} 04$ & 0 & 0 & 0 & 0 & 0 & 2 & & 0 & 0 & 1 & 2 & 0 & 0 & 0 & 0 & 1 & 0 & 1 & $\begin{array}{lll}1 & 1\end{array}$ & 11 & 1 & 0 & 0 & 0 & 0 & 0 & 0 & 0 & 0 & 0 & 0 & 10 & & 0 & 0 & 1 & & 0 & 0 & 0 & 0 & 0 & \\
\hline Yes & Q05 & 0 & 5 & 0 & 0 & 0 & - & & 1 & 2 & 1 & 2 & 0 & 0 & 0 & 0 & 0 & 0 & 0 & 0 & 0 & 0 & 2 & 0 & 0 & 0 & 0 & 0 & 0 & 0 & 0 & 1 & 0 & & 0 & 0 & 0 & 1 & 0 & 0 & 0 & 0 & 0 & 0 \\
\hline Yes & $Q$ & 0 & 0 & 0 & 0 & 1 & 0 & & 0 & 0 & 0 & 0 & 0 & 0 & 0 & 1 & 0 & 0 & 0 & 1 & 1 & 0 & 0 & 0 & 0 & 0 & 0 & 0 & 0 & 0 & 0 & 0 & 0 & & 0 & 0 & 0 & 0 & 0 & 0 & 0 & 0 & 0 & \\
\hline Yes & $Q$ & 0 & 54 & 8 & 4 & 1 & 3 & & 0 & 0 & 3 & 1 & 0 & 12 & 1 & 0 & 0 & 1 & 0 & 0 & 0 & 0 & 0 & 0 & 15 & 2 & 0 & 1 & 2 & 0 & 1 & 0 & 0 & & 0 & 8 & 2 & & 0 & 0 & 0 & 0 & 0 & \\
\hline Yes & Q & 2 & 31 & 9 & 7 & 1 & 5 & & 0 & 3 & 1 & 4 & 0 & 11 & 1 & 0 & 1 & 1 & 0 & 0 & 00 & 0 & 1 & 0 & 3 & 0 & 1 & 1 & 1 & 0 & 1 & 0 & 0 & & 0 & 2 & 0 & 0 & 0 & 0 & 0 & 0 & 0 & \\
\hline Yes & 209 & 0 & 39 & 6 & 7 & 0 & 5 & & 0 & 5 & 0 & 0 & 0 & 14 & 0 & 1 & 0 & 0 & 0 & 0 & 00 & 0 & 1 & 0 & 8 & 0 & 2 & 0 & 1 & 0 & 0 & 0 & 0 & & 0 & 2 & 2 & 2 & 0 & 0 & 0 & 0 & 0 & \\
\hline Yes & Q11 & 0 & 4 & 0 & 2 & 0 & 1 & & 0 & 5 & 1 & 4 & 0 & 1 & 0 & 0 & 0 & 0 & 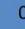 & 1 & 10 & 0 & 0 & 0 & 0 & 1 & 0 & 0 & 0 & 0 & 0 & 0 & 0 & & 0 & 0 & 0 & 1 & 0 & 0 & 0 & 0 & 0 & \\
\hline Yes & 0,12 & 0 & 13 & 1 & 0 & 0 & 2 & 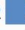 & 0 & 0 & 1 & 0 & 0 & 2 & 0 & 0 & 0 & 0 & 0 & 0 & 0 & 0 & 0 & 0 & 0 & 0 & 0 & 0 & 0 & 0 & 0 & 0 & 0 & & 1 & 0 & 0 & 0 & 0 & 0 & 0 & 0 & 0 & \\
\hline Yes & 0 & 0 & 20 & 4 & 0 & 0 & 3 & & 2 & 3 & 1 & 2 & 0 & 4 & 1 & 1 & 0 & 0 & 1 & 11 & 10 & 0 & 0 & 0 & 3 & 1 & 0 & 0 & 0 & 0 & 0 & 1 & 0 & & 0 & 0 & 1 & 2 & 1 & 0 & 0 & 0 & 0 & \\
\hline Yes & $Q$ & 0 & 52 & 11 & 4 & 2 & 4 & & 3 & 2 & 0 & 1 & 0 & 18 & 1 & 2 & 0 & 0 & 1 & 1 & 00 & 0 & 0 & 0 & 8 & 0 & 1 & 1 & 0 & 0 & 0 & 0 & 0 & & 0 & 0 & 1 & 1 & 0 & 0 & 0 & 0 & 0 & \\
\hline Yes & Q16 & 0 & 2 & 1 & 0 & 1 & 3 & & 0 & 1 & 0 & 1 & 0 & 0 & 0 & $\underline{\sigma}$ & 1 & 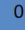 & 0 & 0 & 00 & 0 & 0 & 0 & 0 & 0 & 0 & 0 & 0 & 0 & 0 & 0 & 0 & & 0 & 0 & 0 & 1 & 0 & 0 & 1 & 0 & 0 & \\
\hline Yes & Q & 0 & 32 & 8 & 5 & 1 & 1 & & 1 & 2 & 1 & 1 & 0 & 6 & 1 & 2 & 1 & 0 & 0 & 0 & 0 & 0 & 0 & 0 & 11 & 1 & 2 & u & 0 & 0 & 0 & 0 & 0 & & 0 & 3 & 5 & 0 & 0 & 1 & 0 & 0 & 0 & \\
\hline Yes & Q18 & 0 & 1 & 1 & 2 & 3 & 0 & & 0 & 0 & 0 & 0 & 0 & 0 & 0 & 0 & 0 & 0 & 0 & ) 1 & 1 & 0 & 0 & 0 & 1 & 0 & 0 & 0 & 1 & 0 & 0 & 0 & 0 & & 0 & 1 & 0 & 0 & 0 & 0 & 0 & 0 & 0 & \\
\hline Yes & Q19 & 0 & 74 & 12 & 2 & 2 & 4 & & 1 & 3 & 0 & 3 & 0 & 24 & 1 & 0 & 0 & 0 & 1 & 10 & 0 & 0 & 1 & 1 & 11 & 3 & 0 & 1 & 2 & 0 & 0 & 0 & 0 & & 0 & 5 & 2 & 0 & 0 & 0 & 0 & 0 & 0 & \\
\hline Yes & Q20 & 0 & 37 & 7 & 2 & 1 & 1 & & 2 & 2 & 0 & 0 & 0 & 6 & 1 & 0 & 1 & 1 & 0 & 0 & 0 & 1 & 0 & 0 & 2 & 0 & 1 & 0 & 0 & 0 & 0 & 0 & 0 & & 0 & 1 & 0 & 0 & 0 & 0 & 1 & 0 & 0 & \\
\hline Yes & Q21 & 0 & 0 & 0 & 0 & 0 & 0 & & 1 & 2 & 0 & 0 & 0 & 0 & 0 & 1 & 0 & 0 & 0 & 0 & 0 & 0 & 0 & 0 & 0 & 0 & 0 & 0 & 0 & 0 & 0 & 0 & 0 & & 0 & 0 & 0 & & 0 & 0 & 0 & 0 & 0 & \\
\hline Yes & 0,22 & 0 & 7 & 1 & 2 & 0 & 2 & & 0 & 1 & 0 & 0 & 0 & 4 & 0 & 0 & 0 & U & 0 & 0 & 0 & 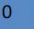 & 0 & 0 & 5 & 0 & 1 & 0 & 0 & 0 & 0 & 0 & 0 & & 0 & 2 & 2 & & 0 & 0 & 0 & 0 & 0 & \\
\hline Yes & Q23 & 0 & 17 & 2 & 6 & 0 & 1 & & 0 & 1 & 2 & 0 & 0 & 5 & 1 & 1 & 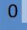 & 1 & 0 & 0 & 0 & 0 & 0 & 0 & 7 & 1 & 1 & 0 & 0 & 1 & 0 & 0 & 0 & & 0 & 1 & 1 & 0 & 0 & 0 & 0 & 0 & 0 & \\
\hline res & Q24 & 0 & 13 & 1 & 4 & 0 & 0 & & 2 & 4 & 0 & 0 & 0 & 3 & 0 & 1 & 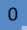 & 0 & 0 & 1 & 1 & 1 & 0 & 0 & 3 & 0 & 2 & 0 & 0 & 0 & 0 & 0 & 0 & & 0 & 3 & 1 & 0 & 0 & 2 & 1 & u & 0 & \\
\hline Yes & Q & 0 & 0 & 0 & 1 & 0 & 2 & & 0 & 1 & 0 & 1 & 0 & 0 & 0 & 0 & 0 & 1 & 0 & 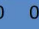 & 0 & 0 & 1 & 0 & 0 & 0 & 0 & 0 & 0 & 0 & 0 & 0 & 0 & & 0 & 0 & 0 & 0 & 0 & 0 & 0 & 0 & 1 & \\
\hline Yes & 0 & 1 & 7 & 0 & 2 & 1 & 3 & & 2 & 2 & 0 & 1 & 0 & 2 & 0 & 1 & 0 & 2 & 0 & 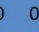 & 0 & 0 & 0 & 0 & 2 & 0 & 0 & 0 & 2 & 0 & 0 & 0 & 0 & & 0 & 0 & 1 & 0 & 0 & 0 & 0 & 0 & 0 & \\
\hline Yes & Q27 & 0 & 5 & 2 & 1 & $\underline{0}$ & & & $\underline{0}$ & 2 & 0 & 1 & $\underline{0}$ & 0 & $\underline{0}$ & & $\underline{0}$ & & 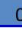 & $\underline{0}$ & $\underline{0}$ & $\underline{4}$ & $u$ & 0 & 0 & 0 & & 0 & 0 & 0 & $\underline{0}$ & $\underline{0}$ & & & 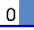 & $\underline{0}$ & 0 & & 0 & 0 & 0 & & & \\
\hline
\end{tabular}


Appendix B, Table Continued

\begin{tabular}{|c|c|c|c|c|c|c|c|c|c|c|c|c|c|c|c|c|c|c|c|c|c|c|c|c|c|c|c|c|c|c|c|c|c|}
\hline \multicolumn{2}{|c|}{ Response Counts } & \multicolumn{11}{|c|}{$\begin{array}{c}\text { Christian } \\
153 \text { Participants NA=(43) }\end{array}$} & \multicolumn{11}{|c|}{$\begin{array}{c}\text { Hindu } \\
52 \text { Participants NA=(15) }\end{array}$} & \multicolumn{10}{|c|}{$\begin{array}{c}\text { Muslim } \\
57 \text { Participants NA=(16) }\end{array}$} \\
\hline Offence & Qnum & NA & 1 & 2 & 3 & 4 & 5 & 6 & 7 & 8 & 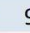 & & NA & 1 & 2 & & 4 & 5 & 6 & 7 & $\varepsilon$ & & 9 & 0 & 1 & 2 & 3 & 4 & & 6 & 7 & & 9 \\
\hline No & Q02 & 0 & 6 & 9 & 15 & 7 & 24 & 14 & 54 & 1 & & 8 & 0 & 3 & 0 & & 0 & 14 & 4 & 1 & & 4 & 3 & 0 & 2 & 3 & 4 & 4 & 7 & 4 & 16 & 3 & 5 \\
\hline No & Q03 & 0 & 13 & 15 & 12 & 4 & 26 & 7 & 20 & 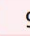 & 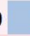 & 1 & 0 & 3 & 0 & & 0 & 8 & 2 & 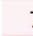 & 7 & 6 & 0 & 0 & 5 & 1 & 3 & U & 4 & 3 & 18 & 1 & 4 \\
\hline No & Q04 & 0 & 3 & 5 & 17 & 2 & 20 & 18 & 47 & 18 & & 6 & 0 & 0 & 0 & & 0 & 5 & 2 & 16 & & & 11 & 1 & 1 & 4 & & 3 & 7 & 3 & 17 & 8 & 4 \\
\hline No & Q05 & 0 & 8 & 16 & 26 & 8 & 27 & 15 & 30 & $\varepsilon$ & & 1 & 0 & 0 & 2 & & 2 & 10 & 3 & 10 & & 3 & 3 & 0 & 6 & 3 & & 2 & 6 & 2 & 16 & 2 & 5 \\
\hline No & Q06 & 0 & 4 & 14 & 11 & 13 & 27 & 23 & 35 & 15 & & 6 & 0 & 1 & 0 & & 0 & 11 & 4 & 15 & & 6 & 2 & 1 & 1 & 6 & & 4 & 6 & 8 & 13 & 3 & 4 \\
\hline No & $\mathrm{Q} 07$ & 0 & 25 & 13 & 11 & 3 & 5 & 5 & 12 & & & 1 & 1 & 0 & 0 & & 2 & 3 & 4 & 1 & & 6 & 5 & 0 & 4 & 2 & & 2 & 3 & 5 & 13 & 3 & 4 \\
\hline No & Q08 & 0 & 9 & 9 & 12 & 4 & 14 & 5 & 17 & & & 7 & 0 & 1 & 1 & & 0 & 3 & 2 & & 3 & 5 & 4 & 0 & 5 & 3 & 3 & 2 & 2 & 6 & 6 & 2 & 5 \\
\hline No & Q09 & 0 & 16 & 10 & 9 & 5 & 12 & 3 & 7 & & 3 & 4 & 0 & 1 & 0 & & 3 & 7 & 1 & 10 & & 1 & 2 & 0 & 3 & 2 & 4 & 3 & 3 & 1 & 10 & 1 & 3 \\
\hline No & Q11 & 0 & 4 & 1 & 9 & 0 & 15 & 10 & 34 & 2 & & 5 & 0 & 0 & 0 & & 0 & 5 & 4 & 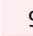 & 9 & 2 & 11 & 0 & 0 & 0 & 2 & 2 & 7 & 2 & 19 & 4 & 8 \\
\hline No & Q12 & 0 & 32 & 9 & 13 & 5 & 21 & 5 & 7 & & 3 & 1 & 0 & 0 & 1 & & 0 & 11 & 3 & 1 & & 3 & 4 & 0 & 2 & 2 & 6 & 3 & 7 & 4 & 11 & 1 & 5 \\
\hline No & Q13 & 0 & 24 & 10 & 14 & 3 & 17 & 8 & 26 & 1 & & 4 & 1 & 4 & 1 & & 1 & 5 & 5 & 5 & 5 & 3 & 3 & 0 & 4 & 2 & & 0 & 4 & 2 & 4 & 2 & 3 \\
\hline No & Q15 & 1 & 10 & 7 & 9 & 2 & 17 & 7 & 9 & 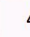 & & 3 & 0 & 1 & 1 & & 0 & 6 & 5 & 1 & & 3 & 4 & 0 & 3 & 4 & & 3 & 3 & 7 & 14 & 0 & 1 \\
\hline No & Q16 & 0 & 34 & 11 & 16 & 3 & 16 & 3 & 14 & & & 3 & 1 & 1 & 3 & & 1 & 11 & 4 & 1 & & 6 & 0 & 1 & 5 & 1 & & 2 & 5 & 1 & 10 & 2 & 4 \\
\hline No & Q17 & 0 & 15 & 14 & 15 & 6 & 23 & 9 & 24 & & & 4 & 0 & 0 & 2 & & 1 & 5 & 6 & 1 & & 4 & 5 & 0 & 4 & 4 & & 3 & 2 & 3 & 4 & 0 & 3 \\
\hline No & Q18 & 0 & 12 & 8 & 27 & 2 & 24 & 9 & 38 & 1 & & 0 & 0 & 2 & 1 & & 0 & 8 & 1 & 10 & & 7 & 7 & 0 & 4 & 5 & 3 & 3 & 7 & 5 & 13 & 1 & 5 \\
\hline No & Q19 & 0 & 11 & 5 & 6 & 0 & 1 & 2 & 2 & & 2 & 2 & 0 & 2 & 1 & & 1 & 3 & 1 & & 7 & 6 & 2 & 0 & 5 & 1 & 1 & 1 & 5 & 2 & 4 & 0 & 3 \\
\hline No & Q20 & 0 & 21 & 13 & 12 & 4 & 9 & 4 & 8 & & t. & 2 & 0 & 3 & 4 & & 0 & 5 & 5 & & 9 & 2 & 3 & 0 & 4 & 3 & 6 & 1 & 7 & 1 & 8 & 0 & 3 \\
\hline No & Q21 & 0 & 32 & 18 & 19 & 7 & 18 & 6 & 18 & & 7 & 4 & 0 & 2 & 1 & & 1 & 5 & 3 & 1 & & 7 & 4 & 0 & 6 & 2 & 7 & 3 & 7 & 1 & 14 & 0 & 3 \\
\hline No & Q22 & 0 & 30 & 8 & 22 & 2 & 14 & 9 & 22 & & 31 & 3 & 0 & 7 & 2 & & 10 & 5 & 3 & 1 & & 4 & 6 & 0 & 3 & 0 & 6 & 0 & 7 & 1 & 9 & 3 & 5 \\
\hline No & Q23 & 0 & 19 & 16 & 16 & 7 & 19 & 8 & 18 & & 51 & 1 & 1 & 3 & 0 & & 4 & 5 & 2 & 1 & & 3 & 5 & 0 & 4 & 1 & 4 & 1 & 2 & 4 & 6 & 1 & 3 \\
\hline No & Q24 & 0 & 6 & 8 & 21 & 9 & 8 & 7 & 38 & 1 & & 9 & 0 & 1 & 0 & & 1 & 9 & 1 & 1 & & 5 & 6 & 0 & 2 & 3 & 3 & 1 & 9 & 6 & 9 & 3 & 7 \\
\hline No & Q25 & 0 & 10 & 12 & 26 & 7 & 29 & 7 & 29 & 1 & & 1 & 0 & 1 & 2 & & 3 & 6 & 2 & 1 & & 4 & 1 & 0 & 3 & 2 & & 4 & 6 & 3 & 13 & 5 & 5 \\
\hline No & Q26 & 1 & 31 & 15 & 20 & 8 & 15 & 10 & 14 & & & 8 & 0 & 2 & 0 & & 1 & 13 & 2 & 1 & & 7 & 2 & 0 & 4 & 1 & 2 & 3 & 4 & 8 & 4 & 2 & 2 \\
\hline No & Q27 & 0 & 13 & 8 & 25 & 8 & 23 & 8 & 31 & 1 & & 3 & 0 & 0 & 0 & & 5 & 8 & 4 & 1 & & 7 & 2 & 0 & 0 & 6 & 5 & 2 & 8 & 3 & 10 & 3 & 3 \\
\hline Yes & $\mathrm{Q} 02$ & 0 & 1 & 1 & 0 & 0 & 0 & 0 & 0 & & ) & 0 & 0 & 0 & 1 & & 10 & 1 & 0 & & 2 & 0 & 0 & 0 & 0 & 1 & 1 & 1 & 1 & 0 & 0 & 1 & 0 \\
\hline Yes & $\mathrm{Q} 03$ & 0 & 3 & 3 & 1 & 0 & 0 & 1 & 1 & & 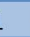 & 1 & 0 & 1 & 0 & & 0 & 2 & 1 & 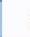 & 2 & 0 & 1 & 0 & 6 & 2 & 2 & 1 & 1 & 2 & 1 & 0 & 0 \\
\hline Yes & Q04 & 0 & 0 & 0 & 0 & 0 & 2 & 0 & 0 & & ) & 0 & 0 & 0 & 0 & 0 & 10 & 0 & 0 & & 4 & 0 & 0 & 0 & 1 & 0 & 0 & 0 & 1 & 1 & 0 & 0 & 0 \\
\hline Yes & Q05 & 0 & 5 & 1 & 1 & 2 & 0 & 1 & 1 & & ) & 0 & 0 & 1 & 1 & 1 & 0 & 3 & 1 & & 1 & 2 & 1 & 0 & 1 & 1 & 1 & 1 & 2 & 1 & 1 & 0 & 0 \\
\hline Yes & Q06 & 0 & 0 & 0 & 0 & 0 & 0 & 1 & 0 & & & 0 & 0 & 0 & 0 & & 0 & 0 & 1 & & 3 & 0 & 0 & 0 & 0 & 0 & & 1 & 1 & 0 & 0 & 0 & 0 \\
\hline Yes & Q07 & 0 & 40 & 8 & 2 & 1 & 0 & 0 & 0 & & & 1 & 1 & 2 & 1 & & 10 & 0 & 1 & & 1 & 1 & 0 & 0 & 4 & 0 & & 0 & 1 & 2 & 0 & 0 & 1 \\
\hline Yes & Q08 & 0 & 40 & 8 & 3 & 0 & 3 & 1 & 2 & & & 2 & 0 & 4 & 1 & & 2 & 4 & 3 & & 2 & 1 & 1 & 0 & 8 & 2 & 1 & 2 & 1 & 0 & 0 & 0 & 0 \\
\hline Yes & Q09 & 0 & 49 & 3 & 2 & 2 & 3 & 0 & 4 & & L & 2 & 0 & 2 & 1 & & 10 & 2 & 4 & & 5 & 2 & 1 & 0 & 8 & 2 & 3 & 0 & 2 & 1 & 1 & 0 & 1 \\
\hline Yes & Q11 & 0 & 7 & 0 & 1 & 0 & 1 & 0 & 5 & & ) & 1 & 0 & 0 & 0 & & 1 & 4 & 2 & & 4 & 1 & 3 & 0 & 0 & 0 & 0 & 0 & 2 & 1 & 3 & 0 & 0 \\
\hline Yes & $\mathrm{Q} 12$ & 0 & 21 & 1 & 1 & 0 & 1 & 1 & 2 & & ) & 1 & 0 & 0 & 0 & 0 & 1 & 0 & 2 & & 1 & 0 & 1 & 0 & 3 & 1 & 0 & 0 & 3 & 2 & 0 & 0 & 0 \\
\hline Yes & Q13 & 0 & 10 & 4 & 2 & 0 & 0 & 1 & 2 & & ) & 0 & 0 & 3 & 1 & 1 & 0 & 3 & c & 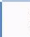 & 3 & 2 & 0 & 0 & 14 & 5 & 0 & 1 & 2 & 0 & 1 & 0 & 1 \\
\hline Yes & Q15 & 0 & 51 & 6 & 7 & 4 & 3 & 4 & 3 & & ) & 1 & 0 & 6 & 0 & & 1 & 1 & 0 & & 2 & 0 & 0 & 0 & 9 & 1 & 1 & 1 & 0 & 0 & 0 & 0 & 0 \\
\hline Yes & Q16 & 0 & 1 & 1 & 0 & 1 & 3 & 0 & 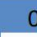 & & ) & 0 & 0 & 0 & 0 & 0 & 10 & 1 & 1 & & 3 & 1 & 1 & 0 & 2 & 0 & 0 & 1 & 2 & 1 & 0 & 0 & 0 \\
\hline Yes & Q17 & 0 & 20 & 4 & 3 & 1 & 1 & 0 & 2 & & ) & 0 & 0 & 2 & 0 & & 10 & 2 & 0 & & 3 & 1 & 0 & 0 & 14 & 3 & & 3 & 0 & 0 & 1 & 0 & 2 \\
\hline Yes & Q18 & 0 & 1 & 0 & 0 & 0 & 1 & 0 & 0 & & ) & 0 & 1 & 1 & 0 & 0 & 10 & 4 & c & & 1 & 0 & 0 & 0 & 0 & 1 & 0 & 0 & 0 & 3 & 1 & 0 & 1 \\
\hline Yes & Q19 & 1 & 72 & 4 & 0 & 1 & 0 & 0 & 2 & & L & 3 & 0 & 7 & 2 & & 1 & 0 & 0 & & 1 & 0 & 1 & 0 & 12 & 1 & 2 & 0 & 1 & 0 & 3 & 0 & 0 \\
\hline Yes & Q20 & 0 & 41 & 5 & 2 & 0 & 1 & 0 & 3 & & 1 & 2 & 0 & 2 & 1 & & 0 & 3 & 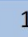 & & 3 & 0 & 0 & 0 & 6 & 4 & 1 & 1 & 2 & 2 & 1 & 1 & 0 \\
\hline Yes & Q21 & 0 & 1 & 0 & 0 & 0 & 0 & 0 & 3 & & ) & 0 & 0 & 2 & 0 & & 0 & 1 & 1 & & 2 & 0 & 0 & 0 & 0 & 0 & 0 & 0 & 1 & 2 & 0 & 0 & 0 \\
\hline Yes & Q22 & 0 & 6 & 1 & 2 & 1 & 0 & 1 & 0 & & ) & 0 & 0 & 4 & 0 & & 10 & 3 & c & & ) & 1 & 0 & 0 & 10 & 2 & 0 & 0 & 1 & 1 & 0 & 0 & 0 \\
\hline Yes & Q23 & 0 & 11 & 0 & 1 & 1 & 0 & 2 & 1 & & ? & 0 & 0 & 0 & 1 & & 10 & 6 & 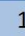 & & 2 & 0 & 0 & 0 & 15 & 2 & 1 & 0 & 4 & 0 & 0 & 2 & \\
\hline Yes & Q24 & 0 & 9 & 3 & 2 & 1 & 2 & 1 & 3 & & & 2 & 0 & 2 & 0 & & 1 & 0 & 1 & & 3 & 0 & 0 & 0 & 1 & 2 & & & 1 & 0 & 2 & 1 & \\
\hline Yes & Q25 & 0 & 0 & 0 & 0 & 0 & 0 & 0 & 2 & & & 0 & 0 & 0 & 0 & & 10 & 1 & 2 & & 2 & 1 & 0 & 0 & 0 & 0 & & 0 & 1 & 2 & 0 & 1 & 0 \\
\hline Yes & Q26 & 0 & 3 & 0 & 1 & 0 & 0 & 0 & 0 & & & 1 & 0 & 2 & 0 & 2 & 0 & 2 & 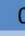 & & 2 & 0 & U & 0 & 9 & 1 & & & 3 & 1 & 1 & 0 & \\
\hline Yes & Q27 & 0 & 2 & 0 & 0 & 0 & 0 & 1 & 2 & & ) & 1 & 0 & 2 & 0 & & 0 & 2 & 1 & & J & 0 & 0 & 0 & 3 & 0 & 1 & 1 & 1 & 1 & 1 & 1 & \\
\hline
\end{tabular}

\section{References}

Abrams, J. R., Bippus, A. M., \& McGaughey, K. J. (2015). 'Gender disparaging jokes: An investigation of sexist-nonstereotypical jokes on funniness, typicality, and the moderating role of ingroup identification'. Humour: International Journal of Humour Research, 28(2), pp. 311-326.

Althusser, L. (1971). 'Ideology and ideological state apparatuses', in Lenin and Philosophy, and Other Essays. Ben Brewster (trans.), London: Verso, pp. 121-176. 
Alwin, D.F., Felson, J.L., Walker E.T. \& Tufis, P.A. (2006). 'Measuring religious identities in surveys'. Public Opinion Quarterly 70(4), pp. 530-564.

Arbuckle, G. A. (2008). Laughing with God: Humor, Culture and Transformation. Collegeville, NM: Liturgical Press.

Berger, P. (1997). Redeeming Laughter: The Comic Dimension of Human Experience. New York: De Gruyter.

Braun, A. \& Preiser, S. (2013). 'The impact of disparaging humour content on the funniness of political jokes'. Humour: International Journal of Humour Research 26(2), pp. 249-275.

Burridge, R.A. (2015). 'The Church of England's Life of Python—or "What the Bishop Saw", in Taylor, J.E. (ed.) Jesus and Brian: Exploring the Historical Jesus and his Times via Monty Python's Life of Brian. London: Bloomsbury, pp. 19-41.

Crump, M, McDonnel J.V., \& Gureckis, T.M. (2013). 'Evaluating Amazon's Mechanical Turk as a tool for experimental behavioural research'. PLOS (8/3), pp. 1-18. DOI: 10.1371/journal.pone. 0057410

Cunningham, W.A., \& Derks, P. (2005). 'Humour appreciation and latency of comprehension'. Humour: International Journal of Humour Research 18(4), pp. 389-403.

Davies, B. \& R. Harré (1990). 'The discursive production of selves'. Journal for the Theory of Social Behaviour 20(1), pp. 43-63.

Elst, K. (2011). 'Humour in Hinduism,' in Geybels, H. \& Van Herck, W. (eds.) Humour and Religion: Challenges and Ambiguities. London: Bloomsbury Academic, pp. 35-53.

Ford, T., Lappi, S.K., O'Connor, E.C. \& Banos, N.C. (2017). 'Manipulating humour styles: Engaging in self-enhancing humour reduces state anxiety'. Humour: International Journal of Humour Research 30(2), pp. 169-191.

Geybels, H. (2011). 'The redemptive power of humour in religion', in Geybels, H. \& Van Herck, W. (eds.) Humour and Religion: Challenges and Ambiguities. London: Bloomsbury Academic, pp. 11-21.

Hall, S. (1996). 'Introduction: Who needs identity?' in Hall S. \& du Gay P. (eds.), Questions of Cultural Identity, London: Sage Publications, pp. 1-17.

Hirzalla, F, \& von Zoonen, L. (2016). "'The Muslims are coming": The enactment of morality in activist Muslim comedy'. Humour: International Journal of Humour Research 29(2), pp. 261-278.

Khan, Y. (2007). "Does Islam have a sense of humour?" BBC News. http://news.bbc.co.uk/go/pr/fr/-/2/hi/uk_news/magazine/7102519.stm.

Kuipers, G. (2011). 'The politics of humour in the public sphere: Cartoons, power and modernity in the first translational humour scandal'. European Journal of Cultural Studies 14(1), pp. 63-80.

Kuschel, K.J. (1994). Laughter: A Theological Reflection. London: SCM Press.

Maiolino, N. \& Kuiper, N. (2016). 'Examining the impact of a brief humour exercise on psychological well-being'. Translational Issues in Psychological Science 2(1), pp. 4-13.

Martin, G.N., Sadler, S.J., Barrett, C.E. \& Beaven, A. (2008). 'Measuring responses to humour: How the testing context affects individuals' reaction to comedy'. Humour: International Journal of Humour Research 21(2), pp. 143-155.

Martin, J, SR. (2011). Between Heaven and Mirth: Why Joy, Humour, and Laughter Are at the Heart of the Spiritual Life. New York: Harper One.

Martin, R.A., Puhlik-Doris, P, Larsen, G., Gray, J. \& Weir K. (2003). 'Individual differences in uses of humour and their relation to psychological well-being: Development of the Humour Styles Questionnaire'. Journal of Research in Personality 37, pp. 48-75.

Marzolph, U. (2011). “The Muslim sense of humour', in Geybels, H. \& van Herck, W. (eds.), Humour and Religion: Challenges and Ambiguities, London: Bloomsbury, pp. 169-187. 
Mason, W. \& Suri. S. (2012). 'Conducting behavioural research on Amazon Mechanical Turk'. Behavioural Research 44(1), pp. 1-23. Doi:10.3758/s13428-011-0124-6.

Merritt, J. (2015). 'Why Christians need to laugh at themselves'. The Atlantic Monthly, December 12, 2015.

https:/www.theatlantic.com/politics/archive/2015/12/why-christians-need-to-laugh-atthemselves/420048/.

Morreall, J. (1999). Comedy, Tragedy, and Religion. Albany, NY: State University of New York Press.

Rand, D. G. (2011). 'The promise of Mechanical Turk: How online labour markets can help theorists run behavioural experiments'. Journal of Theoretical Biology, DOI: 10.1016/j.jtbi.2011.03.004

Rouse, S.V. (2014) 'A reliability analysis of Mechanical Turk data.' Computers in Human Behaviour 43, pp. 304-307.

Saroglou, V. (2002). 'Religion and sense of humour: An a priori incompatibility? Theoretical considerations from a psychological perspective'. Humour: International Journal of Humour Research 15(2), pp. 191-214.

Saroglou, V. \& Jaspard, J.M. (2001). 'Does religion affect humour creation? An experimental study'. Mental Health, Religion \& Culture 4(1), pp. 33-46.

Schweizer, B., \& Ott K.H. (2016). 'Laughter and faith: Do practicing Christians and atheists have different senses of humour?' Humour: International Journal of Humour Research 29(3), pp. 413-438.

Siegel, L. (1987). Laughing Matters: Comic Tradition in India. Chicago: University of Chicago Press.

Stieger, S., Formann, A.K., \& Burger C. (2011). 'Humour styles and their relationship to implicit and explicit self-esteem'. Personality and Individual Differences 50, pp. 747-759.

Wilson, G.D. (1990). 'Ideology and humour preferences'. International Political Science Review 11(4), pp. 461-472.

Yue, X.D. (2011). 'The Chinese ambivalence to humour: Views from undergraduates in Hong Kong and China'. Humour: International Journal of Humour Research 24(4), pp. 463480.

Zimbardo, Z. (2014). 'Cultural politics of humour in (de)normalising islamophobic stereotypes'. Islamophobia Studies Journal 2(1), pp. 59-81. 